NBER WORKING PAPER SERIES

\title{
MONETARY POLICY AND EXCHANGE RATE VOLATILITY IN A SMALL OPEN ECONOMY
}

\author{
Jordi Galí \\ Tommaso Monacelli \\ Working Paper 8905 \\ http://www.nber.org/papers/w8905 \\ NATIONAL BUREAU OF ECONOMIC RESEARCH \\ 1050 Massachusetts Avenue \\ Cambridge, MA 02138 \\ April 2002
}

We are thankful to Nils Bjorsten, Mick Devereux, Philip Lane, Luca Sessa, Lars Svenssson, Guido Tabellini and Alex Wolman for useful comments. We are particularly grateful to Christopher Erceg, who pointed out an error in an earlier version of the paper. We have also benefited from comments by participants in seminars at the EUI, Banca d'Italia, Bocconi, Boston College, Brandeis, Harvard, Rutgers, the Bank of Portugal's Conference on Monetary Economics, NBER Summer Institute, Riksbank, IMF, and the Federal Reserve Board. An earlier version of this paper was circulated under the title "Optimal Monetary Policy and Exchange Rate Volatility in a Small Open Economy." The views expressed herein are those of the authors and not necessarily those of the National Bureau of Economic Research.

(C) 2002 by Jordi Galí and Tommaso Monacelli. All rights reserved. Short sections of text, not to exceed two paragraphs, may be quoted without explicit permission provided that full credit, including (C notice, is given to the source. 
Monetary Policy and Exchange Rate Volatility in a Small Open Economy

Jordi Galí and Tommaso Monacelli

NBER Working Paper No. 8905

April 2002

JEL No. E52, F41

\begin{abstract}
We lay out a small open economy version of the Calvo sticky price model, and show how the equilibrium dynamics can be reduced to a tractable canonical system in domestic inflation and the output gap. We employ this framework to analyze the macroeconomic implications of three alternative monetary policy regimes for the small open economy: domestic inflation targeting, CPI targeting and an exchange rate peg. We show that a key difference among these regimes lies in the relative amount of exchange rate volatility that they entail. We also discuss a special case for which domestic inflation targeting constitutes the optimal policy, and where a simple second order approximation to the utility of the representative consumer can be derived and used to evaluate the welfare losses associated with suboptimal regimes.
\end{abstract}

Jordi Galí

CREI

Universitat Pompeu Fabra

Ramon Trias Fargas 25

08005 Barcelona, Spain

and NBER

jordi.gali@econ.upf.es
Tommaso Monacelli

Boston College 


\section{Introduction}

Much recent work in macroeconomics has involved the development and evaluation of monetary models that bring imperfect competition and nominal rigidities into the dynamic stochastic general equilibrium structure that for a long time had been the hallmark of RBC theory. In the resulting models - often referred to as New Keynesianchanges in monetary settings generally have nontrivial effects on real variables. Monetary policy may thus become a potential stabilization tool, as well as an independent source of economic fluctuations. Not surprisingly, the study of the properties of alternative monetary policy rules (i.e., specifications of how the central bank changes the settings of its instrument in response to changes in macroeconomic conditions) has been a fruitful area of research in recent years and a natural application of the new generation of models. ${ }^{1}$

In the present paper we lay out a small open economy version of a model with Calvo-type staggered price-setting, and use it as a framework to analyze the properties and macroeconomic implications of alternative monetary policy regimes. ${ }^{2}$ The use of a staggered price-setting structure allows for richer dynamic effects of monetary policy than those found in the models with one-period advanced price-setting that are common in the recent literature. ${ }^{3}$ Most importantly, and in contrast with most of the existing literature -where monetary policy is introduced by assuming that some monetary aggregate follows an exogenous stochastic process- we model monetary policy as endogenous, with a short-term interest rate being the instrument of that policy. ${ }^{4}$ For this very reason our framework allows us to model alternative monetary regimes. Furthermore, we believe that our approach accords much better with the practice of modern central banks, and provides a more suitable framework for policy analysis than the traditional one.

Our assumptions on preferences and technology, combined with the Calvo price-

\footnotetext{
${ }^{1}$ The volume edited by Taylor (1999) contains several significant contributions to that literature. See, e.g., Clarida, Galí, and Gertler (1999) for a recent survey.

${ }^{2}$ See, e.g., King and Wolman (1996), Yun (1996), and Woodford (1999), for an analysis of the canonical closed economy Calvo model.

${ }^{3}$ See, e.g., Obstfeld and Rogoff (1995, 1999), Corsetti and Pesenti (2001), Betts and Devereux (2000), and Bacchetta and Van Wincoop (1999)

${ }^{4}$ See Lane (2001) for a survey of the new open economy macroeconomics literature. The introduction of price staggering in an open economy model follows the lead of Kollman (2001) and Chari et al. (1998), though both papers specify monetary policy as exogenous, restricting their analysis to the effects of a monetary shock. A recent exception is given by Obstfeld and Rogoff (1999), who solve for the optimal money supply rule in the context of a model with one-period sticky wages. A more similar methodological approach can be found in Svensson (2000), in which optimal policy is derived from the minimization by the central bank of a quadratic loss function. His model, however, differs from the standard optimizing sticky price model analyzed here in that it assumes a predetermined output and inflation (resulting from their dependence on lagged variables, with a somewhat arbitrary lag structure), and introduces an ad-hoc cost-push shock in the inflation equation (which creates a trade off between the output gap and inflation). Since we wrote and circulated the first version of the present paper there have been several contributions to the literature on monetary policy regimes in open economies, including Schmitt-Grohé and Uribe (2000), Benigno and Benigno (2000), McCallum and Nelson (2000), Corsetti and Pesenti (2001), Parrado and Velasco (2002), and Clarida, Galí, and Gertler (2001), among others.
} 
setting structure and the assumption of complete financial markets, give rise to a highly tractable framework and to simple and intuitive log-linearized equilibrium conditions for the small open economy. In fact, the latter can be reduced to a first order, two-equation dynamical system for domestic inflation and the output gap whose structure, consisting of a new Keynesian Phillips curve and a new IS-type equation, is identical to the one that has been derived (and is often used) for the workhorse model of a closed economy with Calvo-type staggered price setting. ${ }^{5}$ Of course, the coefficients in the open economy's equilibrium also depend on parameters that are specific to the open economy (in our case, the degree of openness and the substitutability between domestic and foreign goods), while the driving forces also include world output fluctuations (which are taken as exogenous to the small open economy). As in the closed economy benchmark, the two equations must be augmented with a third one describing how monetary policy is conducted, in order to close the model.

As hinted above we employ our framework to analyze the macroeconomic implications of alternative monetary policy arrangements for the small open economy: (a) domestic inflation targeting, (b) CPI inflation targeting and (c) an exchange rate peg.

We show that these regimes can be ranked in terms of their implied nominal and real exchange rate volatility. Hence, a policy of domestic inflation targeting, which in our framework can achieve a simultaneous stabilization of the output gap and domestic inflation, implies a substantially larger volatility of both nominal and real exchange rates than CPI targeting and/or an exchange rate peg. In general, a CPI targeting regime delivers equilibrium dynamics that allow to characterize it as a hybrid regime between domestic inflation targeting and an exchange rate peg. In particular, CPI targeting coincides with domestic inflation targeting when the small economy approaches the limiting case of a closed economy, while it tends to mimic the dynamics under a peg when the small economy converges to the highest possible degree of openness.

Next we address the issue of a welfare evaluation of the above policy regimes. We show that under a specific parameterization it is possible to derive a tractable second order approximation of the consumer's utility, which can be used for policy evaluation purposes. In the particular case considered (which entails log-utility and a unit elasticity of substitution between domestic and foreign goods), domestic price stability stands out as the policy regime that is able to replicate the efficient allocation, while both CPI targeting and the exchange rate peg are shown to lead to deviations from the economy's optimal response to shocks. The basic intuition is that the excess smoothness in the nominal exchange rate implied by both these regimes, combined with the assumed inertia in nominal prices, prevents relative prices from adjusting sufficiently fast in response to changes in relative productivity, causing thus a significant deviation from the first best allocation. Interestingly, while CPI targeting has qualitative implications similar to those of an exchange rate peg, the former is shown to dominate the latter from a welfare viewpoint (except for the limiting case of identical consumption baskets).

The remainder of the paper is organized as follows. In section 2 we lay out the basic model. Section 3 derives the equilibrium in log-linearized form and its

\footnotetext{
${ }^{5}$ See, e.g., Clarida, Galí, and Gertler (1999) and Woodford (2000), among others.
} 
canonical representation in terms of output gap and inflation. Section 4 analyzes the macroeconomic implications of alternative monetary policy regimes, such as domestic inflation targeting, CPI inflation targeting and an exchange rate peg. Section 5 analyzes optimal monetary policy in both the world and the small economy under a particular parameterization in the latter, and conducts a welfare evaluation of the alternative monetary regimes. Section 6 concludes.

\section{A Small Open Economy Model}

\subsection{Households}

Our small open economy is inhabited by a representative household who seeks to maximize

$$
E_{0} \sum_{t=0}^{\infty} \beta^{t}\left[U\left(C_{t}\right)-V\left(N_{t}\right)\right]
$$

where $N_{t}$ denotes hours of labor, and $C_{t}$ is a composite consumption index defined by

$$
C_{t}=\left[(1-\alpha)^{\frac{1}{\eta}} C_{H, t}^{\frac{\eta-1}{\eta}}+\alpha^{\frac{1}{\eta}} C_{F, t}^{\frac{\eta-1}{\eta}}\right]^{\frac{\eta}{\eta-1}}
$$

with $C_{H, t}$ and $C_{F, t}$ being indices of consumption of domestic and foreign goods. Such indices are in turn given by the following CES aggregators of the quantities consumed of each type of good:

$$
C_{H, t}=\left(\int_{0}^{1} C_{H, t}(i)^{\frac{\varepsilon-1}{\varepsilon}} d i\right)^{\frac{\varepsilon}{\varepsilon-1}} \quad ; \quad C_{F, t}=\left(\int_{0}^{1} C_{F, t}(i)^{\frac{\varepsilon-1}{\varepsilon}} d i\right)^{\frac{\varepsilon}{\varepsilon-1}}
$$

Notice that under our specification $\eta$ measures the elasticity of substitution between domestic and foreign goods. The elasticity of substitution among goods within each category is given by $\varepsilon$. We assume $\eta>0$ and $\varepsilon>1$.

The maximization of (1) is subject to a sequence of intertemporal budget constraints of the form:

$$
\int_{0}^{1}\left[P_{H, t}(i) C_{H, t}(i)+P_{F, t}(i) C_{F, t}(i)\right] d i+E_{t}\left\{Q_{t, t+1} D_{t+1}\right\} \leq D_{t}+W_{t} N_{t}+T_{t}
$$

for $t=0,1,2, \ldots$, where $P_{H, t}(i)$ and $P_{F, t}(i)$ denote the prices of domestic and foreign good $i$ respectively, $D_{t+1}$ is the nominal payoff in period $t+1$ of the portfolio held at the end of period $t$ (and which includes shares in firms), $W_{t}$ is the nominal wage, and $T_{t}$ denotes lump-sum transfers/taxes. All the previous variables are expressed in units of domestic currency. $Q_{t, t+1}$ is the stochastic discount factor for nominal payoffs. We assume that households have access to a complete set of contingent claims, traded internationally. Notice that money does not appear in either the budget constraint or the utility function: throughout we specify monetary policy in terms of an interest 
rate rule; hence, we do not need to introduce money explicitly in the model. ${ }^{6}$

The optimal allocation of any given expenditure within each category of goods yields the demand functions:

$$
C_{H, t}(i)=\left(\frac{P_{H, t}(i)}{P_{H, t}}\right)^{-\varepsilon} C_{H, t} \quad ; \quad C_{F, t}(i)=\left(\frac{P_{F, t}(i)}{P_{F, t}}\right)^{-\varepsilon} C_{F, t}
$$

for all $i \in[0,1]$, where $P_{H, t} \equiv\left(\int_{0}^{1} P_{H, t}(i)^{1-\varepsilon} d i\right)^{\frac{1}{1-\varepsilon}}$ and $P_{F, t} \equiv\left(\int_{0}^{1} P_{F, t}(i)^{1-\varepsilon} d i\right)^{\frac{1}{1-\varepsilon}}$ are the price indexes for domestic and imported goods.

The optimal allocation of expenditures between domestic and foreign goods implies:

$$
C_{H, t}=(1-\alpha)\left(\frac{P_{H, t}}{P_{t}}\right)^{-\eta} C_{t} \quad ; \quad C_{F, t}=\alpha\left(\frac{P_{F, t}}{P_{t}}\right)^{-\eta} C_{t}
$$

where $P_{t} \equiv\left[(1-\alpha) P_{H, t}^{1-\eta}+\alpha P_{F, t}^{1-\eta}\right]^{\frac{1}{1-\eta}}$ is the consumer price index (CPI). ${ }^{7}$ Notice that, when the price indexes for domestic and foreign goods are equal (as in the steady state described below), parameter $\alpha$ corresponds to the share of domestic consumption allocated to imported goods. It thus represents a natural index of openness.

Once we account for the above optimality conditions, the intertemporal budget constraint can be rewritten as:

$$
P_{t} C_{t}+E_{t}\left\{Q_{t, t+1} D_{t+1}\right\} \leq D_{t}+W_{t} N_{t}+T_{t}
$$

In what follows we specialize the period utility function to take the form $U\left(C_{t}\right) \equiv$ $\frac{C_{t}^{1-\sigma}}{1-\sigma}$ and $V\left(N_{t}\right) \equiv \frac{N_{t}^{1+\varphi}}{1+\varphi}$. Then we can rewrite the remaining optimality conditions for the household's problem as follows:

$$
C_{t}^{\sigma} N_{t}^{\varphi}=\frac{W_{t}}{P_{t}}
$$

which is a standard intratemporal optimality condition, and

$$
\beta\left(\frac{C_{t+1}}{C_{t}}\right)^{-\sigma}\left(\frac{P_{t}}{P_{t+1}}\right)=Q_{t, t+1}
$$

Taking conditional expectations on both sides of (8) and rearranging terms we obtain a conventional stochastic Euler equation:

$$
\beta R_{t} E_{t}\left\{\left(\frac{C_{t+1}}{C_{t}}\right)^{-\sigma}\left(\frac{P_{t}}{P_{t+1}}\right)\right\}=1
$$

\footnotetext{
${ }^{6}$ That modelling strategy has been adopted in much recent research on monetary policy. In it money can be thought of as playing the role of a unit of account only. See Schmitt-Grohé and Uribe (2001) for an analysis of an open economy where the monetary distortion is taken to be non-negligible.

${ }^{7}$ It is usefult to notice, for future reference, that in the particular case of $\eta=1$, the CPI takes the form $P_{t}=P_{H, t}^{1-\alpha} P_{F, t}^{\alpha}$, while the consumption index is given by $C_{t}=\frac{1}{(1-\alpha)^{(1-\alpha)} \alpha^{\alpha}} C_{H, t}^{1-\alpha} C_{F, t}^{\alpha}$
} 
where $R_{t}^{-1}=E_{t}\left\{Q_{t, t+1}\right\}$ is the price of a riskless one-period bond (denominated in domestic currency) and, hence, $R_{t}$ is its gross return.

For future reference it is useful to note that (7) and (9) can be respectively written in log-linearized form as:

$$
\begin{gathered}
w_{t}-p_{t}=\sigma c_{t}+\varphi n_{t} \\
c_{t}=E_{t}\left\{c_{t+1}\right\}-\frac{1}{\sigma}\left(r_{t}-E_{t}\left\{\pi_{t+1}\right\}-\rho\right)
\end{gathered}
$$

where lower case letters denote the $\log$ s of the respective variables, $\rho \equiv-\log \beta$ is the time discount rate, and $\pi_{t} \equiv p_{t}-p_{t-1}$ is CPI inflation (with $p_{t} \equiv \log P_{t}$ ).

In the rest of the world (which, for convenience, we refer to as the world economy) a representative household faces a problem identical to the one outlined above. A set of analogous optimality conditions characterize the solution to the consumer's problem in the world economy. We assume, however, that the size of the small open economy is negligible relative to the rest of the world, which allows us to treat the latter as if it was a closed economy. ${ }^{8}$

\subsubsection{Domestic Inflation, CPI Inflation, the Real Exchange Rate, and the Terms of Trade: Some Identities}

Before proceeding with our analysis of the economy's equilibrium we introduce several assumptions and definitions, and derive a number of identities that are extensively used below.

Thus, log-linearization of the CPI formula around a steady state with $P_{H, t}=P_{F, t}$ yields:

$$
\begin{aligned}
p_{t} & \equiv(1-\alpha) p_{H, t}+\alpha p_{F, t} \\
& =p_{H, t}+\alpha s_{t}
\end{aligned}
$$

where $s_{t} \equiv p_{F, t}-p_{H, t}$ denotes the (log) terms of trade, i.e., the price of foreign goods in terms of home goods. It is useful to note, for future reference, that (10) holds exactly (as opposed to up to a first order approximation) when $\eta=1$.

It follows that domestic inflation -defined as the rate of change in the index of domestic goods prices, i.e., $\pi_{H, t} \equiv p_{H, t+1}-p_{H, t}-$ and CPI-inflation are linked according to

$$
\pi_{t}=\pi_{H, t}+\alpha \Delta s_{t}
$$

which makes the gap between our two measures of inflation proportional to the percent change in the terms of trade, with the coefficient of proportionality given by the index of openness $\alpha$. Our treatment of the rest of the world as an (approximately) closed

\footnotetext{
${ }^{8}$ Formally, this can be done by deriving the optimality conditions for the world consumer under preferences analogous to (2) with a weight $\alpha^{*}$ on goods produced in the small economy. Once the equilibrium conditions are derived and log-linearized, we focus on the limiting case, $\alpha^{*} \rightarrow 0$.
} 
economy (with goods produced in the small open economy (SOE) representing a negligible fraction of the world's consumption basket) implies that the foreign price index $P_{t}^{*}$ (where a star denotes foreign variables henceforth) coincides with $P_{F, t}^{*}$ (i.e., the foreign currency price of foreign goods). Therefore we have $\pi_{t}^{*}=\pi_{F, t}^{*}$, for all $t$, i.e., an equivalence between domestic and CPI inflation holds in the world economy.

In addition, we assume throughout that the law of one price holds, implying that $P_{F, t}(i)=\mathcal{E}_{t} P_{F, t}^{*}(i)$ for all $i \in[0,1]$, where $\mathcal{E}_{t}$ is the nominal exchange rate (the price of foreign currency in terms of home currency), and $P_{F, t}^{*}(i)$ is the price of foreign good $i$ denominated in foreign currency. Integrating over all goods we obtain $P_{F, t}=\mathcal{E}_{t} P_{F, t}^{*}$, or, in log-linear form, $p_{F, t}=e_{t}+p_{F, t}^{*}$. Combining the previous results we can re-write the terms of trade as

$$
s_{t} \equiv e_{t}+p_{t}^{*}-p_{H, t}
$$

Next, let us derive the relationship between the terms of trade and the real exchange rate. We define the (log) real exchange rate as $\mathcal{Q}_{t} \equiv \frac{\mathcal{E}_{t} P_{t}^{*}}{P_{t}}$, i.e. the ratio of CPIs expressed in a common currency. Under our assumptions it follows that

$$
\begin{aligned}
q_{t} & =s_{t}+p_{H, t}-p_{t} \\
& =(1-\alpha) s_{t}
\end{aligned}
$$

where the second equality holds up to a first order approximation.

In words, we have that the (log) real exchange rate is proportional to the (log) terms of trade, with the proportionality coefficient being an inverse function of the degree of openness. Notice that while the law-of-one-price is assumed to hold for each individual good, the real exchange rate may still fluctuate over time as a result of variations in the relative price of domestic vs. world consumption baskets, which will generally differ in composition.

\subsubsection{International Risk Sharing}

Under the assumption of complete securities markets, a first order condition analogous to (8) must also hold for consumers in the foreign country:

$$
\beta\left(\frac{C_{t+1}^{*}}{C_{t}^{*}}\right)^{-\sigma}\left(\frac{P_{t}^{*}}{P_{t+1}^{*}}\right)\left(\frac{e_{t}}{e_{t+1}}\right)=Q_{t, t+1}
$$

Combining (8) and (14), together with the definition of the real exchange rate introduced above, it follows (after iterating) that:

$$
C_{t}=\vartheta C_{t}^{*} \mathcal{Q}_{t}^{\frac{1}{\sigma}}
$$

for all $t$, where $\vartheta$ is a constant that depends on initial conditions. ${ }^{9}$ Taking logs on both sides of (15), using (13), and ignoring the constant term yields the exact relationship:

$$
c_{t}=c_{t}^{*}+\left(\frac{1-\alpha}{\sigma}\right) s_{t}
$$

\footnotetext{
${ }^{9}$ See Appendix 1 for a detailed discussion.
} 
We thus see that the assumption of complete markets at the international level leads to a simple relationship linking consumption at home and abroad and the terms of trade. $^{10}$

\subsubsection{Uncovered Interest Parity and the Terms of Trade}

Under the assumption of complete international financial markets, the equilibrium price (in terms of domestic currency) of a riskless bond denominated in foreign currency is given by $\mathcal{E}_{t} R_{t}^{*}{ }^{-1}=E_{t}\left\{Q_{t, t+1} \mathcal{E}_{t+1}\right\}$. The previous pricing equation can be combined with the domestic bond pricing equation, $R_{t}^{-1}=E_{t}\left\{Q_{t, t+1}\right\}$ to obtain a version of the uncovered interest parity condition:

$$
E_{t}\left\{Q_{t, t+1}\left[R_{t}-R_{t}^{*}\left(\mathcal{E}_{t+1} / \mathcal{E}_{t}\right)\right]\right\}=0
$$

Linearization around a perfect-foresight steady state yields the familiar expression:

$$
r_{t}-r_{t}^{*}=E_{t}\left\{\Delta e_{t+1}\right\}
$$

Combining the definition of the (log) terms of trade with (17) yields the following stochastic difference equation:

$$
s_{t}=\left(r_{t}^{*}-E_{t}\left\{\pi_{t+1}^{*}\right\}\right)-\left(r_{t}-E_{t}\left\{\pi_{H, t+1}\right\}\right)+E_{t}\left\{s_{t+1}\right\}
$$

As we show in Appendix 1, the terms of trade are pinned down uniquely in the perfect foresight steady state. That fact, combined with our assumption of stationarity of the model's driving forces, implies that $\lim _{T \rightarrow \infty} E_{t}\left\{s_{T}\right\}=0$, implying that purchasing power parity (PPP) holds "in the long run." Hence, we can solve (18) forward to obtain:

$$
s_{t}=E_{t}\left\{\sum_{k=0}^{\infty}\left[\left(r_{t+k}^{*}-\pi_{t+k+1}^{*}\right)-\left(r_{t+k}-\pi_{H, t+k+1}\right)\right]\right\}
$$

i.e., variations in the terms of trade are a function of current and anticipated real interest rate differentials.

We must point out that while equation (18) (and (19)) provides a convenient (and intuitive) way of representing the terms of trade dynamics, it is not an additional independent equilibrium condition. In particular, it is easy to check that (18) can be derived by combining the consumption Euler equations for both the domestic and world economies with the risk sharing condition (16) and equation (11).

\section{$2.2 \quad$ Firms}

\subsubsection{Technology}

Each firm produces a differentiated good with a linear technology represented by the production function

$$
Y_{t}(i)=A_{t} N_{t}(i)
$$

\footnotetext{
${ }^{10} \mathrm{~A}$ similar relationship holds in many international RBC models. See, e.g., Backus and Smith (1993).
} 
where $a_{t} \equiv \log A_{t}$ follows an $\operatorname{AR}(1)$ process $a_{t}=\rho_{a} a_{t-1}+\varepsilon_{t}$. Hence, the (nominal) marginal cost will be common across firms and given by

$$
m c_{t}^{n}=-\nu+w_{t}-a_{t}
$$

where $\nu \equiv-\log (1-\tau)$, with $\tau$ being an employment subsidy whose role is discussed later in more detail.

Let $Y_{t} \equiv\left[\int_{0}^{1} Y_{t}(i)^{1-\frac{1}{\varepsilon}} d i\right]^{\frac{\varepsilon}{\varepsilon-1}}$ represent an index for aggregate output, analogous to the one introduced for consumption. It is useful, for future reference, to derive an approximate aggregate production function relating the previous index to aggregate employment. Hence, notice that

$$
N_{t} \equiv \int_{0}^{1} N_{t}(i) d i=\frac{Y_{t} U_{t}}{A_{t}}
$$

where $U_{t} \equiv \int_{0}^{1} \frac{Y_{t}(i)}{Y_{t}} d i$. In Appendix 3 we show that equilibrium variations in $u_{t} \equiv$ $\log U_{t}$ around the perfect foresight steady state are of second order. Thus, and up to a first order approximation, we have an aggregate relationship

$$
y_{t}=n_{t}+a_{t}
$$

Firms in the rest of the world are assumed to have access to an identical technology, with $(\log )$ productivity following an exogenous process $a_{t}^{*}=\rho_{a}^{*} a_{t-1}^{*}+\varepsilon_{t}^{*}$, where $\left\{\varepsilon_{t}^{*}\right\}$ is white noise, possibly correlated with $\left\{\varepsilon_{t}\right\}$. Finally, an approximate aggregate relationship between output and employment identical to (20) also holds for the world economy.

\subsubsection{Price setting}

We assume that firms set prices in a staggered fashion, as in Calvo (1983). Hence, a measure $1-\theta$ of (randomly selected) firms sets new prices each period, with an individual firm's probability of reoptimizing in any given period being independent of the time elapsed since it last reset its price. As we show in Appendix 2, the optimal price-setting strategy for the typical firm resetting its price in period $t$ can be approximated by the (log-linear) rule:

$$
\bar{p}_{H, t}=\mu+(1-\beta \theta) \sum_{k=0}^{\infty}(\beta \theta)^{k} E_{t}\left\{m c_{t+k}^{n}\right\}
$$

where $\bar{p}_{H, t}$ denotes the (log) of newly set domestic prices, and $\mu \equiv \log \left(\frac{\varepsilon}{\varepsilon-1}\right)$, which corresponds to the log of the (gross) markup in the steady state (or, equivalently, the optimal markup in a flexible price economy). An analogous price setting rule obtains for firms operating in the rest of the world.

Hence, we see that the pricing decision in our model (as in its closed economy counterpart) is a forward-looking one. The reason is simple: firms that are adjusting prices in any given period recognize that the price they set will remain effective for a (random) number of periods. As a result they set the price as a markup over 
a weighted average of expected future marginal costs, instead of looking at current marginal cost only. Notice that in the flexible price limit (i.e., as $\theta \rightarrow 0$ ), we recover the familiar markup rule $\bar{p}_{H, t}=\mu+m c_{t}^{n}$.

The price setting problem facing firms in the rest of the world is also identical to that of domestic firms, and leads to an optimal price setting rule analogous to (21). For simplicity, and without loss of generality, we assume throughout our analysis that the degree of price stickiness in the world economy, $\theta^{*}$, is identical to that in the small open economy.

\section{Equilibrium}

\subsection{Aggregate Demand and Output Determination}

\subsubsection{World Consumption and Output}

First we describe how consumption and output are determined in the world economy. As mentioned above, in that economy the preferences of the representative household are identical to those introduced above, but with a negligible weight on the goods imported from the small economy. The log-linearized Euler equation, combined with the market clearing condition $y_{t}^{*}=c_{t}^{*}$, implies:

$$
y_{t}^{*}=E_{t}\left\{y_{t+1}^{*}\right\}-\frac{1}{\sigma}\left(r_{t}^{*}-E_{t}\left\{\pi_{t+1}^{*}\right\}-\rho\right)
$$

Hence, as in the standard New Keynesian closed economy model, world output is inversely related to current and anticipated world real interest rates. The previous equation, often referred to as the new IS equation, is one of the key building blocks of optimizing sticky price models. Next we derive a version of such an equation for the small open economy.

\subsubsection{Consumption and Output in the Small Open Economy}

Let $C_{H, t}^{*}(i)$ denote the world demand for the domestic good $i$. Then market clearing in the small economy requires

$$
\begin{aligned}
Y_{t}(i) & =C_{H, t}(i)+C_{H, t}^{*}(i) \\
& =\left(\frac{P_{H, t}(i)}{P_{H, t}}\right)^{-\varepsilon}\left[\left(\frac{P_{H, t}}{P_{t}}\right)^{-\eta}(1-\alpha) C_{t}+\left(\frac{P_{H, t}}{\mathcal{E}_{t} P_{t}^{*}}\right)^{-\eta} \alpha^{*} Y_{t}^{*}\right] \\
& =\left(\frac{P_{H, t}(i)}{P_{H, t}}\right)^{-\varepsilon} \vartheta Y_{t}^{*}\left[\left(\frac{P_{H, t}}{P_{t}}\right)^{-\eta}(1-\alpha) \mathcal{Q}_{t}^{\frac{1}{\sigma}}+\left(\frac{P_{H, t}}{\mathcal{E}_{t} P_{t}^{*}}\right)^{-\eta} \alpha\right]
\end{aligned}
$$

for all $i \in[0,1]$ and all $t$, where the second equality follows from (4),and (5) (together with an analogous expression for the rest of the world), and the third equality makes use of (15) and the condition $\frac{\alpha^{*}}{\vartheta}=\alpha$ required for a zero trade balance in the steady state (see appendix 1). 
obtain

Plugging (23) into the definition of aggregate output $Y_{t} \equiv\left[\int_{0}^{1} Y_{t}(i)^{1-\frac{1}{\varepsilon}} d i\right]^{\frac{\varepsilon}{\varepsilon-1}}$ we

$$
Y_{t}=\vartheta Y_{t}^{*} \mathcal{S}_{t}^{\eta}\left[(1-\alpha) \mathcal{Q}_{t}^{\frac{1}{\sigma}-\eta}+\alpha\right]
$$

which, up to a first order approximation, can be rewritten as:

$$
y_{t}=y_{t}^{*}+\frac{\omega_{\alpha}}{\sigma} s_{t}
$$

where $\omega_{\alpha} \equiv 1+\alpha(2-\alpha)(\sigma \eta-1)>0$, and where the subscript $\alpha$ is meant to emphasize the dependence of $\omega_{\alpha}$ on the degree of openness of the economy. Notice that in the particular case of $\sigma \eta=1$ we obtain the exact log-linear relationship:

$$
y_{t}=y_{t}^{*}+\eta s_{t}
$$

Alternatively, if we use (16) to substitute out for $s_{t}$ in (25) we can derive a simple expression for domestic consumption as a weighted average of domestic and world output, which will hold as a first order approximation:

$$
c_{t}=\Phi_{\alpha} y_{t}+\left(1-\Phi_{\alpha}\right) y_{t}^{*}
$$

where $\Phi_{\alpha} \equiv \frac{1-\alpha}{\omega_{\alpha}}>0$. Notice that in the particular case of $\alpha=0$, corresponding to a closed economy, we have $\omega_{0}=1, \Phi_{0}=1$, and hence $c_{t}=y_{t}$ for all $t$. Furthermore, in the particular case of $\sigma \eta=1$, we can combine the exact relationships (16) and (26) to obtain:

$$
c_{t}=(1-\alpha) y_{t}+\alpha y_{t}^{*}
$$

Finally we can combine (27), (11), and (25), with the consumer's log-linear Euler equation to derive a difference equation for domestic output in terms of domestic real interest rates and world output:

$$
y_{t}=E_{t}\left\{y_{t+1}\right\}-\frac{\omega_{\alpha}}{\sigma}\left(r_{t}-E_{t}\left\{\pi_{H, t+1}\right\}-\rho\right)+\left(\omega_{\alpha}-1\right) E_{t}\left\{\Delta y_{t+1}^{*}\right\}
$$

By solving (29) forward, it is easy to see the level of output in the small economy is negatively related to current and anticipated domestic real interest rates. It is also related to anticipated world output growth (which in turn depends on expected future world real interest rates), with a coefficient $\omega_{\alpha}-1$ whose sign is positive (negative) if $\sigma \eta>1(<1)$.

\subsubsection{The Trade Balance}

Let $n x_{t} \equiv\left(\frac{1}{Y}\right)\left(Y_{t}-\frac{P_{t}}{P_{H, t}} C_{t}\right)$ denote net exports in terms of domestic output, expressed as a fraction of steady state output $Y$. In the particular case of $\sigma=\eta=1$, it follows from (15) and (24) that $P_{H, t} Y_{t}=P_{t} C_{t}$ for all $t$, thus implying a balanced trade 
at all times. More generally, a first-order approximation yields $n x_{t} \simeq y_{t}-c_{t}-\alpha s_{t}$ which combined with (25) and (27) implies

$$
\begin{aligned}
n x_{t} & =\left(1-\Phi_{\alpha}\right)\left(y_{t}-y_{t}^{*}\right)-\alpha s_{t} \\
& =\frac{\alpha \Lambda}{\omega_{\alpha}}\left(y_{t}-y_{t}^{*}\right)
\end{aligned}
$$

where $\Lambda \equiv(2-\alpha)(\sigma \eta-1)+(1-\sigma)$.

Again, in the special case of $\sigma=\eta=1$ we have $n x_{t}=0$ for all $t$, though the latter property will also hold for any configuration of parameters such that $\Lambda=0$. As we will see below, when that condition is satisfied, the objective function for the small open economy's monetary authority collapses into that of the closed economy counterpart. More generally, the sign of the relationship between the output differential and net exports is ambiguous, depending on the sign of $\Lambda$, which is in turn increasing in both $\sigma$ and $\eta$. If $\Lambda>0$, a positive output differential (favorable to the small economy) generates a trade surplus, whereas the sign of the reversed if $\Lambda<0$. Notice, also, the sign of $\Lambda$ determines the sign of the effect on net exports of a change in the terms of trade, given that $n x_{t}=\frac{\alpha \Lambda}{\sigma} s_{t}$. Therefore the condition $\Lambda>0$ is our model's analog to the Marshall-Lerner conditions.

\subsection{The Supply Side: Marginal Cost and Inflation Dynamics}

\subsubsection{Marginal Cost and Inflation Dynamics in the Rest of the World}

Under our assumptions, the dynamics of inflation in the world economy correspond to those of a closed economy characterized by staggered price setting à la Calvo. By combining the optimal price setting equation (21) corresponding to the world economy, with the log-linear version of the equation describing the evolution of the aggregate price level, one can derive the difference equation: ${ }^{11}$

$$
\pi_{t}^{*}=\beta E_{t}\left\{\pi_{t+1}^{*}\right\}+\lambda \widehat{m c_{t}^{*}}
$$

where $\widehat{m c}_{t}^{*} \equiv m c_{t}^{*}+\mu$ denotes the (log) real marginal cost, expressed as a deviation from its steady state value $(-\mu)$, while the slope coefficient is given by $\lambda \equiv \frac{(1-\theta)(1-\beta \theta)}{\theta}$.

Notice that, under our assumptions the (log) real marginal cost is given by

$$
\begin{aligned}
m c_{t}^{*} & =-\nu^{*}+\left(w_{t}^{*}-p_{t}^{*}\right)-a_{t}^{*} \\
& =-\nu^{*}+\sigma c_{t}^{*}+\varphi n_{t}^{*}-a_{t}^{*} \\
& =-\nu^{*}+(\sigma+\varphi) y_{t}^{*}-(1+\varphi) a_{t}^{*}
\end{aligned}
$$

where $\nu^{*} \equiv-\log \left(1-\tau^{*}\right)$, with $\tau^{*}$ denoting a constant employment subsidy whose role is discussed below.

\footnotetext{
${ }^{11}$ The derivation of the inflation equation in the world economy follows that of the small open economy found in Appendix 2 (as well as in numerous papers in the literature), with suitable change of notation. See, e.g., Galí and Gertler (1999) or Sbordone (1999) for an empirical assessment of the implied inflation dynamics.
} 


\subsubsection{Marginal Cost and Inflation Dynamics in the Small Open Economy}

In the small open economy, the dynamics of domestic inflation in terms of real marginal cost are described by an equation analogous to the (closed) world economy counterpart. Hence,

$$
\pi_{H, t}=\beta E_{t}\left\{\pi_{H, t+1}\right\}+\lambda \widehat{m c}_{t}
$$

The determination of the real marginal cost as a function of domestic output in the small open economy differs somewhat from that in the closed economy, due to the existence of a wedge between output and consumption, and between domestic and consumer prices. We indeed have

$$
\begin{aligned}
m c_{t} & =-\nu+w_{t}-a_{t}-p_{H, t} \\
& =-\nu+\left(w_{t}-p_{t}\right)+\left(p_{t}-p_{H, t}\right)-a_{t} \\
& =-\nu+\sigma c_{t}+\varphi n_{t}+\alpha s_{t}-a_{t} \\
& =-\nu+\sigma y_{t}^{*}+\varphi y_{t}+s_{t}-(1+\varphi) a_{t}
\end{aligned}
$$

where $\nu \equiv-\log (1-\tau)$, where the last equality makes use of (16). Thus, we see that marginal cost is increasing in the terms of trade and world output. Both variables end up influencing the real wage, through the wealth effect on labor supply resulting from their impact on domestic consumption. In addition, changes in the terms of trade have a direct effect on the product wage, for any given real wage. The influence of technology (through its direct effect on labor productivity) and of domestic output (through its effect on employment and, hence, the real wage) is analogous to that observed in the closed economy.

Finally, using (25) to substitute for $s_{t}$, we can rewrite the previous expression for the real marginal cost in terms of domestic output and productivity, as well as world output:

$$
m c_{t}=-\nu+\left(\frac{\sigma}{\omega_{\alpha}}+\varphi\right) y_{t}+\sigma\left(1-\frac{1}{\omega_{\alpha}}\right) y_{t}^{*}-(1+\varphi) a_{t}
$$

Before turning our attention to the analysis of the properties of such an equilibrium under alternative monetary policy regimes, we describe a convenient representation of the model's equilibrium dynamics, in terms of the output gap and inflation.

\subsection{Equilibrium Dynamics: A Canonical Representation}

In this section we show that the linearized equilibrium dynamics for the small open economy have a representation in terms of output gap and domestic inflation analogous to that of its closed economy counterpart. That representation, which we refer to as the canonical one, has provided the basis for the analysis and evaluation of alternative policy rules in much of the recent literature. Let's define the output gap $\widetilde{y}_{t}$ as the deviation of $(\log )$ output $y_{t}$, from its natural level $\bar{y}_{t}$, where the latter is in turn defined as the equilibrium level of output in the absence of nominal rigidities (and conditional on output in the rest of the world). Formally, 


$$
\widetilde{y}_{t} \equiv y_{t}-\bar{y}_{t}
$$

An analogous definition holds for the world output gap, i.e. $\widetilde{y}_{t}^{*} \equiv y_{t}^{*}-\bar{y}_{t}^{*}$. For expository convenience we start by deriving the equilibrium dynamics for the world economy.

\subsubsection{World Equilibrium Dynamics}

Under flexible prices, real marginal costs (and hence markups) in the world economy will be constant over time, and given by $m c^{*} \equiv-\mu$, the level that would obtain under flexible prices. One can thus use (32), evaluated at the flexible price equilibrium, to determine the natural level of world output:

$$
\bar{y}_{t}^{*}=\Omega_{0}+\Gamma_{0} a_{t}^{*}
$$

where $\Omega_{0} \equiv \frac{v^{*}-\mu}{\sigma+\varphi}$, and $\Gamma_{0} \equiv \frac{1+\varphi}{\sigma+\varphi}$. In addition one can derive a simple relationship between real marginal cost (in terms of deviations from its steady state value) and the output gap:

$$
\widehat{m c}_{t}^{*}=(\sigma+\varphi) \widetilde{y}_{t}^{*}
$$

The latter result, combined with (31), gives rise to the so-called New Keynesian Phillips curve (or NKPC for short):

$$
\pi_{t}^{*}=\beta E_{t}\left\{\pi_{t+1}^{*}\right\}+\kappa_{0} \widetilde{y}_{t}^{*}
$$

where $\kappa_{0} \equiv \lambda(\sigma+\varphi)$. We can also rewrite (22) in terms of the world output gap:

$$
\widetilde{y}_{t}^{*}=E_{t}\left\{\widetilde{y}_{t+1}^{*}\right\}-\frac{1}{\sigma}\left(r_{t}^{*}-E_{t}\left\{\pi_{t+1}^{*}\right\}-\overline{r r}_{t}^{*}\right)
$$

where $\overline{r r}_{t}^{*} \equiv-\sigma\left(1-\rho_{a}^{*}\right) \Gamma_{0} a_{t}^{*}+\rho$ is the natural (or Wicksellian) expected real rate of interest, i.e., the one that would prevail in a flexible price equilibrium. Notice that (37) and (38), combined with a monetary policy rule determining the world interest rate fully describe the equilibrium dynamics of the world inflation and output gap.

\subsubsection{Equilibrium Dynamics for the Small Open Economy}

The natural level of output in the small open economy can be found after imposing $m c_{t}=-\mu$ for all $t$ and solving for domestic output in equation (35):

$$
\bar{y}_{t}=\Omega_{\alpha}+\Gamma_{\alpha} a_{t}+\Theta_{\alpha} y_{t}^{*}
$$

where $\Omega_{\alpha} \equiv \frac{\omega_{\alpha}(v-\mu)}{\sigma+\omega_{\alpha} \varphi}, \Gamma_{\alpha} \equiv \frac{\omega_{\alpha}(1+\varphi)}{\sigma+\varphi \omega_{\alpha}}>0$, and $\Theta_{\alpha} \equiv \frac{\sigma\left(1-\omega_{\alpha}\right)}{\sigma+\varphi \omega_{\alpha}}$.

It also follows from (35) that the real marginal cost and the output gap will be related according to: 


$$
\widehat{m c}_{t}=\left(\frac{\sigma}{\omega_{\alpha}}+\varphi\right) \widetilde{y}_{t}
$$

which we can combine with (33) to derive a NKPC for the small open economy in terms of the output gap:

$$
\pi_{H, t}=\beta E_{t}\left\{\pi_{H, t+1}\right\}+\kappa_{\alpha} \widetilde{y}_{t}
$$

where $\kappa_{\alpha} \equiv \lambda\left(\frac{\sigma}{\omega_{\alpha}}+\varphi\right)$. Notice that for $\alpha=0$ the slope coefficient is given by $\kappa_{0} \equiv \lambda(\sigma+\varphi)$ and (40) corresponds to the standard, closed economy NKPC. The same is true for the $\sigma \eta=1$ case, for the latter condition implies that $\omega_{\alpha}=1$. More generally, we see that the form of the Phillips equation for the open economy corresponds to that of the closed economy, at least as far as domestic inflation is concerned. The degree of openness affects the dynamics of inflation only through its influence on the size of the slope of the Phillips curve, i.e., the size of the inflation response to any given variation in the output gap. In the open economy, a change in domestic output has an effect on marginal cost through its impact on employment (captured by $\varphi$ ), and the terms of trade (captured by $\frac{\sigma}{\omega_{\alpha}}$, which is a function of the degree of openness and the substitutability between domestic and foreign goods). In particular, under the assumption that $\sigma \eta>1$, an increase in openness lowers the size of the adjustment in the terms of trade necessary to absorb a change in domestic output (relative to world output), thus dampening the impact of the latter on marginal cost and inflation.

Using (29) it is straightforward to derive a version of the new IS equation for the open economy in terms of the output gap:

$$
\widetilde{y}_{t}=E_{t}\left\{\widetilde{y}_{t+1}\right\}-\frac{\omega_{\alpha}}{\sigma}\left(r_{t}-E_{t}\left\{\pi_{H, t+1}\right\}-\overline{r r}_{t}\right)
$$

where

$$
\overline{r r}_{t} \equiv \rho-\frac{\sigma(1+\varphi)\left(1-\rho_{a}\right)}{\sigma+\varphi \omega_{\alpha}} a_{t}-\varphi \Theta_{\alpha} E_{t}\left\{\Delta y_{t+1}^{*}\right\}
$$

is the small open economy's natural rate of interest.

Thus we see that the small open economy's equilibrium is characterized by an IS-type equation similar to that found in the closed economy. Two differences can be pointed out, however. First, the degree of openness influences the sensitivity of the output gap to interest rate changes. In particular, if $\sigma \eta>1$, an increase in openness raises that sensitivity. Second, openness makes the natural interest rate depend on expected world output growth, in addition to domestic productivity.

\section{Simple Monetary Policy Rules for the Small Open Economy}

In the present section we analyze the macroeconomic implications of three alternative monetary policy regimes for the small open economy: a policy that aims at fully 
stabilizing domestic inflation (domestic inflation targeting, or DIT, for short), a policy that stabilizes CPI inflation (CPI inflation targeting, CIT for short) and a policy that pegs the exchange rate to the world currency (a PEG, for short). In all cases we assume that the world monetary authority succeeds in fully stabilizing world prices and the output gap; hence, we assume $\widetilde{y}_{t}^{*}=\pi_{t}^{*}=0$ for all $t$. As discussed below that is the policy which is optimal for the closed economy under our assumptions.

\subsection{Domestic Inflation Targeting}

In this section we characterize the equilibrium processes for the different variables of our small open economy, under the assumption that the domestic pursue a domestic inflation targeting policy (DIT), which implies:

$$
\widetilde{y}_{t}=\pi_{H, t}=0
$$

all $t$. This in turn implies $y_{t}=\bar{y}_{t}$ and $r_{t}=\overline{r r}_{t}$ for all $t$, with all the remaining variables matching their natural level all the time.

In particular, it is evident from inspecting equation (39) that, under DIT, output in the small open economy always increases in response to a positive technology shock at home. The sign of the response to a rise in world output is ambiguous, however. That response is negative if $\omega_{\alpha}>1$, which in turn requires that the expenditureswitching effect resulting from the real appreciation associated with a lower world interest rate dominates the positive direct demand effect; that phenomenon obtains whenever $\sigma \eta>1$, which in turn implies $\omega_{\alpha}>1$.

Given that under DIT both domestic and world inflation are zero, it follows that $e_{t}=s_{t}$, i.e., the nominal exchange rate moves one to one with the terms of trade. Hence, under DIT, the nominal exchange rate inherits all the statistical properties of the terms of trade, including its stationarity (and thus its reversion to a constant mean). ${ }^{12}$ More specifically, by combining (25) with (39) and (36) it is possible to derive the equilibrium behavior of the nominal exchange rate as

$$
\begin{aligned}
e_{t} & =\frac{\sigma}{\omega_{\alpha}}\left(\bar{y}_{t}-\bar{y}_{t}^{*}\right) \\
& =\frac{\sigma(1+\varphi)}{\sigma+\varphi \omega_{\alpha}}\left(a_{t}-a_{t}^{*}\right)
\end{aligned}
$$

where the second equality holds up to a constant term. Hence we see that the nominal exchange rate varies with the productivity differential, depreciating (appreciating) in response to a relative increase in domestic (world) productivity.

Of course, stationarity does not necessarily imply low volatility. The latter will be a function of the relative variances of domestic and world productivity, as well as the correlation between the two. More precisely, the variance of the nominal exchange rate under flexible prices will be proportional to

$$
\left(\sigma_{a}-\sigma_{a^{*}}\right)^{2}+2 \sigma_{a} \sigma_{a^{*}}\left(1-\rho_{a, a^{*}}\right)
$$

\footnotetext{
${ }^{12}$ The stationarity of the terms of trade is, in turn, an implication of the stationarity of the productivity differential coupled with our assumption of complete asset markets.
} 
where $\sigma_{a}$ and $\sigma_{a^{*}}$ denote the standard deviation of domestic and world productivity, and $\rho_{a, a^{*}}$ their correlation. Hence, we see that the required volatility of the nominal exchange rate under DIT is increasing with the extent of the asymmetry between the two shocks, both in terms of their magnitude (represented by the first term) and their comovement (measured by the second term).

In addition we can also derive the implied equilibrium process for the CPI level. Given the constancy of domestic and world prices it is given by:

$$
\begin{aligned}
p_{t} & =\alpha e_{t} \\
& =\frac{\alpha \sigma(1+\varphi)}{\sigma+\varphi \omega_{\alpha}}\left(a_{t}-a_{t}^{*}\right)
\end{aligned}
$$

where the second equality follows from (42). Thus, we see that under domestic inflation targeting the CPI level will vary with the productivity differential, and will inherit its statistical properties. The same is true for the real exchange rate, which under the present regime will be given by $q_{t}=(1-\alpha) e_{t}$.

\subsection{CPI Inflation Targeting}

Under the regime analyzed here the monetary authority of the small economy seeks to stabilize CPI inflation (as opposed to domestic inflation). Formally, such a policy requires

$$
\pi_{t}=0
$$

for all $t$. Under the assumption that the world economy pursues an optimal policy (implying that the foreign price level is constant), and setting $p_{t}=p_{t}^{*}=0$ for all $t$ (without loss of generality), we can write:

$$
p_{H, t}=-\alpha s_{t}
$$

thus implying common dynamics for the domestic price level and the terms of trade. Using the previous expression to substitute for $s_{t}$ in (25), and plugging the resulting equation into (35), we obtain:

$$
m c_{t}=-\frac{1}{\alpha}\left(1+\frac{\varphi \omega_{\alpha}}{\sigma}\right) p_{H, t}-(1+\varphi)\left(a_{t}-a_{t}^{*}\right)
$$

By substituting the latter equality in (25), plugging the resulting equation into (35) and combining with the inflation equation (33) one can derive the following stochastic second order difference equation describing the equilibrium behavior of the domestic price level:

$$
\gamma_{c} p_{H, t}=p_{H, t-1}+\beta E_{t}\left\{p_{H, t+1}\right\}-\lambda(1+\varphi)\left(a_{t}-a_{t}^{*}\right)
$$

where $\gamma_{c} \equiv 1+\beta+\frac{\lambda}{\alpha}\left(1+\frac{\varphi \omega_{\alpha}}{\sigma}\right)$. Under the simplifying assumption that $\rho_{a}=\rho_{a}^{*}$ this equation has a unique stationary representation given by 


$$
p_{H, t}=\xi_{c} p_{H, t-1}-\zeta_{c}\left(a_{t}-a_{t}^{*}\right)
$$

where $\xi_{c} \equiv \frac{1}{2 \beta}\left(\gamma_{c}-\sqrt{\gamma_{c}^{2}-4 \beta}\right) \in(0,1)$, and $\zeta_{c} \equiv \frac{\lambda \xi_{c}(1+\varphi)}{\left(1-\xi_{c} \beta \rho_{a}\right)}>0$.

Notice that under CIT the sign of the response of domestic prices to a change in relative productivity is unambiguously negative. The reason is simple: a rise in domestic productivity leads to a real depreciation of the terms of trade and, given domestic prices, to an increase in CPI inflation (see (11)). The desired stabilization of CPI inflation is therefore achieved by inducing a decline in domestic prices and a smaller real depreciation, both of which can be attained by means of a negative output gap.

By combining (47) and (45) it is then possible to derive the equilibrium processes for the terms of trade and in turn for the nominal and real exchange rates (notice that under CIT we have $q_{t}=e_{t}$ all $t$, i.e., nominal and real exchange rate coincide). In particular we will have

$$
e_{t}=q_{t}=-\frac{1-\alpha}{\alpha} p_{H, t}
$$

Thus, under CIT, the equilibrium nominal exchange rate must be stationary and, given the evolution of the domestic price level, it must depreciate in response to a rise in productivity. Furthermore, and in contrast with the DIT regime, the exchange rate (nominal and real) will display some endogenous persistence, beyond that inherited from the productivity differential.

\subsection{An Exchange Rate Peg}

The third monetary arrangement for the small open economy consists of a permanent (and credible) exchange rate peg vis a vis the rest of the world. In the context of our model, this is equivalent to the adoption of the world currency by the small economy, with the corresponding relinquishment of an autonomous monetary policy. Again, for simplicity, we maintain the assumption of an optimal monetary policy for the world economy. That policy is based on world aggregates, and is not affected by the joining of the world monetary union by our small economy, given the negligible size of the latter.

In the absence of capital controls, an implication of monetary integration is the equalization of the domestic interest rate to the world interest rate. Furthermore, constancy of the nominal exchange rate and world prices implies that $s_{t}=-p_{H, t}$ and $q_{t}=-p_{t}$, for all $t$.

Employing a similar strategy to the one followed in the case of CPI targeting above, we can derive a second order difference equation for the domestic price level:

$$
\gamma_{e} p_{H, t}=p_{H, t-1}+\beta E_{t}\left\{p_{H, t+1}\right\}-\lambda(1+\varphi)\left(a_{t}-a_{t}^{*}\right)
$$

where $\gamma_{e} \equiv 1+\beta+\lambda\left(1+\frac{\varphi \omega_{\alpha}}{\sigma}\right)$. The unique stationary representation for $p_{H, t}$ in this case is given by:

$$
p_{H, t}=\xi_{e} p_{H, t-1}-\zeta_{e}\left(a_{t}-a_{t}^{*}\right)
$$


where $\xi_{e} \equiv \frac{1}{2 \beta}\left(\gamma_{e}-\sqrt{\gamma_{e}^{2}-4 \beta}\right) \in(0,1)$, and $\zeta_{e} \equiv \frac{\lambda \xi_{e}(1+\varphi)}{\left(1-\xi_{e} \beta \rho_{a}\right)}>0$.

The stationarity of the domestic price level is again a direct implication of the stationarity of the terms of trade, given the constancy of the nominal exchange rate and the world price level. Notice that the sign and qualitative pattern of the response of domestic prices under a peg is identical to the one derived for a CIT regime. In particular, it displays some endogenous persistence beyond that inherited from variations in the productivity differential. The difference between the two responses is easy to characterize: notice that $\gamma_{e}<\gamma_{c}$, which in turn implies $\xi_{e}>\xi_{c}$ and $\zeta_{e}>\zeta_{c}$. Accordingly, an exchange rate peg leads to a stronger and more persistent adjustment of domestic prices (and, hence, of the output gap) in response to a shock in the productivity differential, relative to a CPI targeting regime.

Furthermore, and given $e_{t}=p_{t}^{*}=0$ for all $t$, it follows that the CPI level is proportional to the domestic price level:

$$
p_{t}=(1-\alpha) p_{H, t}
$$

and, hence, it shares its statistical properties and response patterns. In particular, and in contrast with a DIT regime, the CPI must fall under a peg in response to a rise in the productivity differential.

Let us point out, as a general remark, that there is an interesting similarity across the alternative regimes considered here: they all imply a stationary price level and nominal exchange rate. That feature is in stark contrast with the non-stationarity of both variables observed in the data. That contrast may suggest that neither regime provides a good approximation to the policies pursued by actual economies. On the other hand, it is worth noticing that both the DIT and CIT regimes can be considered as limiting cases of simple linear Taylor-type rules of the form $r_{t}=\rho+\phi_{\pi} \pi_{H, t}$ (for DIT) and $r_{t}=\rho+\phi_{\pi} \pi_{t}$ (for CIT), when $\phi_{\pi} \rightarrow \infty$. Under such "flexible" inflation targeting regimes, the implied equilibrium dynamics would result in non-stationary price level and nominal exchange rate. ${ }^{13}$ By way of contrast, the stationarity of the price level under an exchange rate peg would also carry over to a more flexible, managed system in which the nominal exchange rate was allowed to fluctuate around a constant central parity. In that case, the stationarity of the terms of trade (a consequence of our assumptions of complete asset markets) and the stability of world prices would guarantee that both domestic and consumer prices remained stationary.

\subsection{Dynamic Effects of a Domestic Productivity Shock}

In this section we present some quantitative results based on a calibrated version of our model economy. Let's first state the main assumptions underlying our baseline calibration, which we take as a benchmark. We set $\sigma$ equal to unity, which corresponds to a $\log$ utility specification, and $\eta$ equal to 1 . We assume $\varphi=3$, which implies a labor supply elasticity of $\frac{1}{3}$, and a value for the steady-state markup $\mu=1.2$, which implies that $\varepsilon$, the elasticity of substitution between differentiated goods, is 6 . Parameter

\footnotetext{
${ }^{13}$ These results are, for the sake of brevity of exposition, not displayed here but are available upon request from the authors.
} 
$\theta$ is set equal to 0.75 , a value consistent with an average period of one year between price adjustments. We assume $\beta=0.99$, which implies a riskless annual return of about 4 percent in the steady state. We set $\rho_{a}=0.9$ and then calibrate $\sigma_{a}^{2}$ so that the standard deviation of the natural level of output in the (closed) world economy is 2 percent, which we take as a (reasonable) benchmark. All the previous parameters are assumed to take identical values in the small open economy and the world economy. In addition, the small economy is characterized by an openness index $\alpha$ for which we assume a value of 0.4 ; the latter corresponds roughly to the share of imports in GDP for Canada. Furthermore, the correlation between the domestic and world shocks is set to 0.77 , a value that we estimate using quarterly productivity data for Canada and the U.S.

We start by describing the dynamic effects of a domestic productivity shock on a number of macroeconomic variables. Figure 1 displays the impulse responses to a unit innovation in $a_{t}$ under the three regimes considered. By construction, domestic inflation and the output gap remain unchanged under DIT (solid line), whereas they both fall under CIT (dashed) and the peg (short dashes). We also see that the shock leads to a persistent reduction in the domestic interest rate as it is needed in order to support the transitory expansion in consumption and output consistent with the flexible price allocation. Given the constancy of the world nominal interest rate the uncovered interest parity implies an initial nominal depreciation followed by expectations of a future appreciation, as reflected in the response of the nominal exchange rate. Relative to the other regimes, the constancy of domestic prices under DIT then accounts for a larger real depreciation and therefore for a further expansion in demand and output through a rise in net exports (not shown here). Notice also that CPI inflation rises at first (with this rise being proportional to the degree of openness), but becomes negative ever after, in accordance with the exchange rate response.

It is interesting to contrast the implied dynamic behavior of several macro variables under CIT (dashed line) with the one under DIT. Notice, in particular, that stabilization of CPI inflation leads to a deviation from DIT on two margins: a decline in domestic prices and a more muted depreciation of both the nominal and the real exchange rate, both on impact and along the transition. That, in turn, requires a more contractionary policy (a higher interest rate), which is reflected in a higher nominal (and real) interest rate. Under our calibration this implies an overshooting in the interest rate, which rises at first and then falls over time. ${ }^{14}$ As shown above, this policy arrangement is consistent with stationarity of both the price level and the exchange rate. Yet both output gap and inflation fall sharply under CIT relative to DIT, so that their implied volatility largely exceeds the one under DIT. As discussed below, and under some special assumptions, that higher volatility is unambiguously associated with a welfare loss, relative to DIT. ${ }^{15}$

\footnotetext{
${ }^{14}$ Notice that this initial rise of the nominal intrest rate (for a given world interest rate), followed by a subsequent fall, is still consistent with the observed depreciation of the nominal exchange rate on impact. It is, in fact, the behavior of current and expected future interest rate differentials that matters for the current nominal exchange rate, as can be easily seen by solving the uncovered interest parity condition forward.

${ }^{15}$ We develop our results on welfare later. Notice, however, that the cost of dampening exchange
} 
Finally the same figure displays the corresponding impulse responses under an exchange rate peg. Notice that the responses of output gap and inflation are qualitatively similar to the CIT case. However, the impossibility of lowering the nominal rate and letting the currency depreciate, as would be needed in order to support the expansion in consumption and output required in order to replicate the flexible price allocation, determines an amplification of the same responses and therefore further volatility in inflation and output gap. Again the stationarity of the price level implied by the peg requires that the initial, short-lived deflation is eventually followed by a period of persistent (albeit low) inflation. That pattern, combined with the constancy of the nominal rate, implies a decline in expected long real rates (not shown in the figure), with the consequent expansion in consumption and a real depreciation. However the real depreciation is in this case much more muted on impact (though more persistent), given that it can be achieved only through an adjustment in relative prices.

In order to complement our quantitative analysis, Table 1 reports the standard deviation of several key variables under alternative monetary policy regimes. For each case we display statistics for three scenarios: domestic shocks only, foreign shocks only, and both foreign and domestic shocks. The numbers confirm some of the findings that were already evident from visual inspection of the impulse responses. Hence, we see that a DIT regime requires substantially more volatility in the nominal exchange rate than a CIT regime, independently of the source of shocks. The PEG regime amplifies both output gap and inflation volatility relative to DIT, with the CIT regime lying somewhere in between. Notice also that in the scenario with both shocks the implied volatility of the real and nominal exchange rate is substantially lower than the one of output and, hence, far lower than the relative volatility observed in the data. ${ }^{16}$ Furthermore the real exchange rate is more stable under an exchange rate peg than under any other policy regime. That finding, which is consistent with the evidence of Mussa (1986), points to the existence of "excess smoothness" in real exchange rates under fixed exchange rates. That feature is a consequence of the inability of prices (which are sticky) to compensate for the constancy of the nominal exchange rate. ${ }^{17}$

\subsubsection{Monetary regimes and Macroeconomic Volatility: Sensitivity Analy- sis}

To conclude our quantitative section we conduct a sensitivity analysis of the second moments of selected variables to the calibration of three key parameters. Figures 2, 3 and 4 display the effect on the volatility of output gap, inflation, nominal and real exchange rates of varying, respectively, the elasticity of substitution between domestic and foreign goods $\eta$, the degree of openness $\alpha$, and the index of price stickiness $\theta$. In

rate volatility (and therefore the relative ranking between DIT and CIT ) may be a function of the lags with which exchange rate movements affect prices, i.e., of the degree of pass-through. Intuitively, the lower the degree of pass-through, the smaller (ceteris paribus) the cost of short-run relative price inertia, and therefore the more desirable to pursue a policy of CIT relative to DIT.

${ }^{16}$ The standard deviation of the real exchange rate relative to that of output reported in Backus et al. (1985) is 1.91 for the U.S., 2.0 for Canada, 1.76 for Germany, and 1.95 for the U.K..

${ }^{17}$ See Monacelli (1999) for a detailed analysis of the implications of fixed exchange rates. 
each panel we maintain our benchmark calibration $\sigma=\eta=1$ (with the exception of Figure 2 where $\eta$ can vary) and compare the implied volatility under the three monetary regimes analyzed so far.

Several interesting observations are in order. To begin with, notice that in all cases the ranking between rules is robust to the choice of parameter values. A clear trade-off emerges between the stabilization of both the nominal and real exchange rates, on the one hand, and the stabilization of inflation and the output gap on the other. Thus, the DIT regime achieves full stabilization of output gap and inflation, but at the cost of boosting the instability of the exchange rates. The converse is true for the exchange rate peg, with CIT emerging as a hybrid regime.

In particular, notice (see Figure 2) that an increase in the elasticity of substitution between domestic and foreign goods lowers the volatility of both the nominal and the real exchange rate. In the limit, as $\eta$ becomes arbitrarily large (i.e., as goods become perfectly substitutable), that volatility approaches zero, since the size of the necessary relative price adjustments in response to shocks is dampened.

Consider next the effect of increasing the degree of openness $\alpha$, as displayed in Figure 3. Notice first that under our benchmark calibration both DIT and PEG regimes imply that output gap and inflation volatility are independent of openness, so that in both these cases the equilibrium dynamics is isomorphic to the one of a closed economy. This can be easily seen by recalling that $p_{H, t}=0$ under DIT and by inspecting equation (50) for the case of a PEG, which is independent of $\alpha$ when $\sigma=\eta=1$. Yet the same is not true for the CIT regime, which corresponds to DIT for $\alpha=0$ and converges to a PEG when $\alpha \rightarrow 1$. As it is clear from equation (47), the dynamics of the domestic price level depend on $\alpha$, even in the special case of $\sigma=\eta=1$. In fact, when $\alpha \rightarrow 1$, and given our assumption of complete international asset markets, the consumption basket in the small economy corresponds to that of the world economy, with the law of one price implying a constant real exchange rate (and therefore aggregate PPP). Given the fact that $q_{t}=e_{t}-p_{t}$, it must be the case that CIT and the PEG must be equivalent.

Interestingly, and unlike the conventional wisdom on the effects of exchange rate instability on trade, a higher degree of openness (i.e., trade intensity) has a negative effect on the volatility of the real exchange rate. ${ }^{18}$ Under risk sharing, in fact, and for given fluctuations in relative consumption baskets, a larger degree of openness requires smaller fluctuations in real relative prices.

Finally, we look at the effect of varying the degree of price stickiness (i.e., the probability of not resetting prices $\theta$ ). Figure 4 reports the corresponding volatility measures. As we approach full rigidity of prices (i.e., $\theta \rightarrow 1$ ) inflation volatility is reduced, but at the cost of boosting output gap volatility. In this case, in fact, full price rigidity is imposed as a constraint, and firms are prevented from adjusting prices even if they wished to do so. This implies large fluctuations in markups and therefore in the output gap. Notice also that, under DIT, the volatility of the nominal exchange rate is independent of $\theta$, as implied by equation (42). An analogous invariance holds for the real exchange rate (or any other variable). Intuitively, the constraints on price adjustment are not binding under that regime, since all firms manage to maintain

\footnotetext{
${ }^{18}$ See Hau (2000) for an empirical assessment of this point, in the context of a different model.
} 
their desired markup at all times, at unchanged prices. Equilibrium allocations and relative prices are thus independent of the degree of price stickiness.

On the other hand, under the CIT regime, as $\theta$ approaches 1 , the volatility of both the nominal and real exchange rates approaches zero as the rigidity of prices increases, as implied by equation (49). The same is true for the real exchange rate under a PEG.

\section{Optimal Monetary Policy}

In this section we derive and discuss the properties of the equilibrium dynamics when both the domestic and world monetary authorities pursue an optimal monetary policy. Our analysis is restricted to a special case-which corresponds to the baseline calibration considered above-for which a second order approximation to the welfare of the representative consumer can be easily derived.

We start by recalling the form of the welfare-based objective function in the closed economy, which is the one relevant to the world economy in our case. Then we proceed with the corresponding analysis for the small open economy, trying to identify the issues that are specific to it.

\subsection{Optimal Monetary Policy in the World Economy}

Following Rotemberg and Woodford (1999) we assume that the fiscal authority in the (closed) world economy fully neutralizes the distortions associated with firms' market power by means of a constant employment subsidy $\tau^{*}$. Under that assumption it is easy to show that the flexible price equilibrium allocation is optimal in the (closed) world economy. To see this, notice that the optimal allocation must maximize $U\left(C_{t}^{*}\right)-V\left(N_{t}^{*}\right)$ subject to $C_{t}^{*}=A_{t}^{*} N_{t}^{*}$, for all $t$, where the constraint already imposes an even allocation of resources across firms (a necessary condition for efficiency, and which is satisfied in the flexible price allocation since all firms will be setting the same prices). The associated first order condition is given by $V^{\prime}\left(N_{t}^{*}\right)=U^{\prime}\left(C_{t}^{*}\right) A_{t}^{*}$.

On the other hand, the flexible price equilibrium satisfies

$$
\begin{aligned}
1-\frac{1}{\varepsilon} & =\overline{M C}_{t}^{*} \\
& =\frac{\left(1-\tau^{*}\right)}{A_{t}^{*}} \frac{V^{\prime}\left(\bar{N}_{t}^{*}\right)}{U^{\prime}\left(\bar{C}_{t}^{*}\right)}
\end{aligned}
$$

Hence, by setting $\tau^{*}=\frac{1}{\varepsilon}$ (or, equivalently, $\nu^{*}=\mu$ ) the world policymaker guarantees the optimality of the flexible price equilibrium allocation. It follows that the optimal monetary policy in such an environment is the one that succeeds in closing the output gap and fully stabilizing prices, i.e. $\widetilde{y}_{t}^{*}=\pi_{t}^{*}=0$ at $t=0$.

Notice that the equilibrium level of world output associated with that optimal policy corresponds to its natural level, as derived in (36). Given (38), we can easily derive an expression for the interest rate that supports the optimal allocation in the 
world economy: ${ }^{19}$

$$
\begin{aligned}
r_{t}^{*} & =\overline{r r}_{t}^{*} \\
& =\rho-\sigma\left(1-\rho_{a}^{*}\right) \Gamma_{0} a_{t}^{*}
\end{aligned}
$$

\subsection{Optimal Monetary Policy in the Small Open Economy: A Special Case}

As noted by Corsetti and Pesenti (2001a), among others, in an open economy there is a second factor that distorts the incentives of the monetary authority (in addition to market power): the possibility of influencing the terms of trade in a way beneficial to domestic consumers. This possibility is a consequence of the imperfect substitutability between domestic and foreign goods, combined with sticky prices (which render monetary policy non-neutral). ${ }^{20}$ Below we assume the presence of an employment subsidy that exactly offsets the combined effects of market power and the terms of trade distortions in the steady state. That assumption rules out the existence of an average inflation (or deflation) bias, and allows us to focus on the policies consistent with a zero average inflation, in a way analogous to the world economy.

Let us first characterize the optimal allocation from the viewpoint of a social planner facing the resource constraints that the small open economy is subject to in equilibrium (vis a vis the rest of the world), and given our assumption of complete markets. In that case, that optimal allocation must maximize $U\left(C_{t}\right)-V\left(N_{t}\right)$ subject to the technological constraint $Y_{t}=A_{t} N_{t}$ and the consumption/output possibilities set $C_{t}=f\left(Y_{t}, Y_{t}^{*}\right)$ (with the latter embedding the risk sharing condition (15), as well as the equilibrium relationship between the terms of trade, and domestic and foreign output implicit in (24)).

The derivation of a tractable, analytical solution requires that we restrict ourselves to the special case of $\sigma=\eta=1$. In that case, and as shown above, we have the exact expression $C_{t}=Y_{t}^{1-\alpha}\left(\vartheta Y_{t}^{*}\right)^{\alpha}$. The optimal allocation (from the viewpoint of the small open economy, which takes world output as given) must satisfy,

$$
V^{\prime}\left(N_{t}\right) N_{t}=(1-\alpha) U^{\prime}\left(C_{t}\right) C_{t}
$$

which, under the assumed preferences, implies a constant employment $N=(1-\alpha)^{\frac{1}{1+\varphi}}$.

On the other hand, the flexible price equilibrium in the small open economy satisfies:

$$
1-\frac{1}{\varepsilon}=\overline{M C}_{t}
$$

\footnotetext{
${ }^{19}$ In order for equation (51) to be interpretable as an optimal rule, one could add an extra term (e.g., $\varphi_{\pi} \pi_{t}^{*}$ with $\varphi_{\pi}>1$ ). In that case we would eliminate the indeterminacy that would otherwise be associated with an interest rate that depends on exogenous variables only. Notice however that such a term will be zero in equilibrium. See, e.g., Woodford (2000), for a detailed discussion.

${ }^{20}$ This distinguishes our analysis from Goodfriend and King (2001) who assume that the price of domestic goods is determined in the world market.
} 


$$
\begin{aligned}
& =\frac{(1-\tau)}{A_{t}}\left(\frac{\bar{Y}_{t}}{\vartheta \bar{Y}_{t}^{*}}\right)^{\alpha} \frac{V^{\prime}\left(\bar{N}_{t}\right)}{U^{\prime}\left(\bar{C}_{t}\right)} \\
& =(1-\tau) \bar{N}_{t}^{1+\varphi}
\end{aligned}
$$

Hence, by setting $\tau$ such that $(1-\tau)(1-\alpha)=1-\frac{1}{\varepsilon}$ is satisfied (or, equivalently, $\nu=\mu+\log (1-\alpha))$ the small open economy's policy maker guarantees the optimality of the flexible price equilibrium allocation. As in the closed economy case, the optimal monetary policy requires stabilizing the output gap (i.e., $\widetilde{y}_{t}=0$, for all $t$ ). Equation (40) then implies that domestic prices are also stabilized under that optimal policy $\left(\pi_{H, t}=0\right.$ for all $\left.t\right)$. Thus, in the special case under consideration, domestic inflation targeting is indeed the optimal policy.

\subsubsection{The Welfare Costs of Alternative Simple Rules}

As we show in Appendix 3, and for the special case considered in the present section, a second order approximation to the utility of the representative consumer in the small open economy, expressed as a fraction of steady state consumption, can be written as:

$$
\mathbb{W} \equiv-\frac{(1-\alpha)}{2} \sum_{t=0}^{\infty} \beta^{t}\left[\frac{\varepsilon}{\lambda} \pi_{H, t}^{2}+(1+\varphi) \widetilde{y}_{t}^{2}\right]+t . i . p .+o\left(\|a\|^{3}\right)
$$

Taking unconditional expectations on (52) and letting $\beta \rightarrow 1$, the expected welfare losses of any policy that deviated from strict inflation targeting can be written in terms of the variances of inflation and the output gap:

$$
\mathbb{V} \equiv \frac{(1-\alpha)}{2}\left[\frac{\varepsilon}{\lambda} \operatorname{var}\left(\pi_{H, t}\right)+(1+\varphi) \operatorname{var}\left(\widetilde{y}_{t}\right)\right]
$$

Table 2 reports the welfare losses associated with the two simple rules analyzed in the previous section: CPI targeting and an exchange rate peg. In both cases we report welfare numbers for the usual three scenarios: domestic shocks only, foreign shocks only and both shocks. There are four panels in this table. The top panel reports welfare losses in the case of our benchmark parameterization, while the remaining three panels display the effects of lowering, respectively, the steady-state markup, the elasticity of labor supply and both. All entries are to be read as percentage units of steady state consumption, and in deviation from the first best represented by DIT.

Under our baseline calibration both rules are suboptimal since they involve nontrivial deviations from domestic price stability. As it stands clear, the exchange rate peg implies in all scenarios a substantially larger deviation from the first best relative to CIT, as already arguable from the quantitative evaluation of the second moments conducted above. However, and as is usually the case in welfare exercises of this sort found in the literature, the implied welfare losses are quantitatively small for both policy regimes. This is particularly true in the two-shock scenario, which implies a lower volatility of both the nominal and real exchange rate relative to the scenarios with one shock only. 
Consider next the effect of lowering, respectively, the steady-state markup to 1.1, by setting $\varepsilon=11$ (which implies a larger penalization of inflation variability in the loss function) and the elasticity of labor supply to 0.1 (which implies a larger penalization of output gap variability). Although the relative ranking between CIT and PEG is unaltered, the effect is a substantial magnification of welfare losses relative to the benchmark case, especially in the third exercise where both parameters are lowered simultaneously. However, as a percentage of steady state consumption, the losses continue to remain quantitatively small.

\subsection{Sensitivity Analysis: the Role of Openness and of Co- movement with World Shocks}

In this section we investigate to what extent the welfare-based ranking of the monetary policy regimes discussed above may be sensitive to the calibration of two central parameters characterizing the small open economy: the degree of openness and the correlation between domestic and world shocks.

Figure 5 displays how our welfare measure associated with alternative policies varies with $\alpha$, the openness index. Notice, first, that the relative ranking among monetary policy regimes is invariant to the degree of openness. In particular, for all $\alpha \in(0,1)$, both CIT and the exchange rate peg imply substantially larger welfare losses relative to DIT, with the former always dominating the latter.

In the limiting case of $\alpha=0$, the domestic economy becomes closed and DIT coincides with CIT. As a result, their associated welfare measures also coincide. Only the exchange rate peg implies a larger welfare loss in that limiting case.

When $\alpha \rightarrow 1$, and given our assumption of complete international asset markets, the consumption basket in the small economy corresponds to that of the world economy, with the risk sharing condition implying a constant real exchange rate and a perfect correlation between domestic and world consumption. In that context there are no possible welfare gains (or losses) associated with deviations from a DIT policy, as implied by the welfare function (52). Therefore both CIT and the PEG converge to DIT as a limiting case, and under this scenario all rules replicate the efficient allocation.

Notice also that CIT dominates the exchange rate peg for any $\alpha$ value (other than 1). In particular, the exchange rate peg is the only regime for which welfare is monotonically increasing in openness. Under that regime, the lower is $\alpha$, the larger is the variation in domestic prices required to bring about any relative price adjustment.

Therefore the key intuition to be applied to the analysis of all the rules above is that, as long as aggregate PPP does not hold (which is the case for values of $\alpha<1$ ), a lower degree of openness makes limiting exchange rate flexibility more costly by boosting the volatility of inflation and output gap.

Finally, Figure 6 illustrates the effect on welfare of varying the cross-country correlation of shocks under alternative monetary regimes. Notice that, for all the rules considered, the deviation from DIT converges to zero as the shock correlation approaches unity. For both CIT policies and the exchange rate peg the cost of limiting the flexibility of relative prices is inversely related to the correlation of shocks. In the 
limit, as the correlation with world shocks becomes perfect, the cost of mimicking the interest rate decision made by the (optimizing) world monetary authority vanishes.

\section{Summary and Concluding Remarks}

The present paper has developed and analyzed a model of a small open economy with staggered price setting à la Calvo. We have shown that the equilibrium dynamics for the small open economy model have a canonical representation (in terms of domestic inflation and the output gap) analogous to that of its closed economy counterpart. More precisely, their representations differ only in two respects: (a) some coefficients of the equilibrium dynamical system for the small open economy depend on parameters that are specific to the latter (the degree of openness and the substitutability between domestic and foreign goods), and (b) the natural levels of output and interest rates in the small open economy are a function of both domestic and foreign disturbances. In particular, the closed economy is nested in the small open economy model, as a limiting case.

We have then used our framework to analyze the properties of three alternative monetary regimes for the small open economy: (a) domestic inflation targeting, (b) CPI inflation targeting, and (c) an exchange rate peg. Our analysis point to a clear tradeoff between the stabilization of both the nominal and real exchange rates, on the one hand, and the stabilization of inflation and the output gap on the other. Hence a policy of domestic inflation targeting, which achieves a simultaneous stabilization of both domestic prices and the output gap, entails a substantially larger volatility of nominal and real exchange rates relative to a policy of CPI targeting and/or an exchange rate peg. The converse is true for the latter regime. In general a regime of CPI targeting delivers equilibrium dynamics that allow us to characterize it as a hybrid regime, somewhere between domestic inflation targeting and a peg. In particular, CPI targeting coincides with domestic inflation targeting in the limiting case of a closed economy, while it mimics the dynamics under a peg when domestic and foreign consumption baskets are identical (which happens when the degree of openness reaches its highest limit).

We have also shown that, under a specific parameterization, a tractable second order approximation to the utility of the small open economy's consumer can be derived, and the welfare level implied by alternative monetary policy rules can be evaluated. In that case, the implied loss function is analogous to the one applying to the corresponding closed economy, which penalizes fluctuations in domestic inflation and the output gap. In particular, under our assumptions, domestic inflation targeting emerges as the optimal policy regime. Relative to the latter, CPI inflation targeting and an exchange rate peg deliver higher welfare losses, due to the excess smoothness of real exchange rates that they involve. Quantitatively, however, the welfare losses involved are small.

Our framework lends itself to several extensions. First, it is important to emphasize that domestic price stability (along with fully flexible exchange rates) stands out as the welfare maximizing policy in the particular case of log-utility and unitary elasticity of substitution between domestic and foreign goods that we analyze here. 
The derivation of a more general welfare function for the small open economy would allow a more thorough analysis and quantitative evaluation of the optimal monetary policy and should certainly be the object of future research.

Second, a two-country version of the framework developed here would allow us to analyze a number of issues that cannot be addressed with the present model, including the importance of spillover effects in the design of optimal monetary policy, the potential benefits from monetary policy coordination, and the implications of exchange rate stabilization agreements. Recent work by Benigno and Benigno (2001), Clarida et al. (2001), and Pappa (2001) has already made some inroads on that front. Our current work in progress seeks to recast that analysis in terms of the simple canonical model representation developed in the present paper.

A further interesting extension would involve the introduction, along with sticky prices, of sticky nominal wages in the small open economy. As pointed out by Erceg, Henderson and Levin (2000), the simultaneous presence of both forms of nominal rigidity introduces an additional tradeoff that renders strict price inflation targeting policies suboptimal. It may be interesting to analyze how that tradeoff would affect the ranking across monetary policy regimes of the present paper.

Finally, it is worth noticing that our analysis features complete exchange rate pass-through of nominal exchange rate changes to prices of imported (or exported) goods. Some of the implications of less than complete pass-through associated with local currency pricing by exporters and importers have already been analyzed by several authors in the context of two-country models with one-period, price-setting in advance (see, e.g., Bacchetta and van Wincoop (2001), Devereux and Engle (2000), and Corsetti and Pesenti (2001b)). It would be interesting to explore some of those implications (e.g., for the nature of the optimal monetary policy problem and the relative performance of alternative policy regimes) in the context of the simple small open economy with staggered price-setting proposed here. 


\section{Appendix 1: The Steady State}

Next we characterize the perfect foresight, zero inflation steady state of our small open economy model, taking $Y^{*}$ as given and setting $A_{t} \equiv 1$, for all $t$. We use variables without time subscripts to refer to steady state values. Markups are constant in the steady state at the level $\frac{\varepsilon}{\varepsilon-1}$, implying $\frac{(1-\tau) W}{P_{H}}=\left(1-\frac{1}{\varepsilon}\right)$. The latter fact, combined with $(7)$ and the identity $\frac{P}{P_{H}}=\left[(1-\alpha)+\alpha \mathcal{S}^{1-\eta}\right]^{\frac{1}{1-\eta}} \equiv g(\mathcal{S})$, implies $C^{\sigma} Y^{\varphi}=\frac{\left(1-\frac{1}{\varepsilon}\right)}{g(\mathcal{S})(1-\tau)}$.

In steady state, the risk sharing condition $(15)$ takes the form $C^{\sigma}=\left(\vartheta Y^{*}\right)^{\sigma} q(\mathcal{S})$ where $q(\mathcal{S}) \equiv \frac{\mathcal{S}}{g(\mathcal{S})}$ links the real exchange rate and the terms of trade in the steady state. One can easily check that $g^{\prime}(\mathcal{S})>0$ and $q^{\prime}(\mathcal{S})>0$. Combining the previous results we obtain (up to a multiplicative constant):

$$
Y=\left(\frac{1-\frac{1}{\varepsilon}}{\mathcal{S}\left(\vartheta Y^{*}\right)^{\sigma}(1-\tau)}\right)^{\frac{1}{\varphi}} \equiv H\left(\mathcal{S}, Y^{*}\right)
$$

Notice that $H_{s}<0$, with $\lim _{s \rightarrow 0} H\left(\mathcal{S}, Y^{*}\right)=+\infty$ and $\lim _{s \rightarrow \infty} H\left(\mathcal{S}, Y^{*}\right)=0$.

On the other hand, market clearing requires

$$
\begin{aligned}
Y & =C_{H, t}+C_{H, t}^{*} \\
& =(1-\alpha) g(\mathcal{S})^{\eta} C+\alpha^{*} \mathcal{S}^{\eta} Y^{*}
\end{aligned}
$$

The latter expression can be combined with (15) to yield:

$$
Y=(1-\alpha) g(\mathcal{S})^{\eta} \vartheta Y^{*} q(\mathcal{S})^{\frac{1}{\sigma}}+\alpha^{*} \mathcal{S}^{\eta} Y^{*} \equiv J\left(\mathcal{S}, Y^{*}\right)
$$

Notice that function $J$ satisfies $J_{s}>0$, and $\lim _{s \rightarrow 0} J\left(\mathcal{S}, Y^{*}\right)=0$ and $\lim _{s \rightarrow \infty} J\left(\mathcal{S}, Y^{*}\right)=$ $+\infty$. Hence, given a value for $Y^{*}$ and $\vartheta,(54)$ and (55) jointly (and uniquely) determine the steady state values for $\mathcal{S}$ and $q(\mathcal{S})$, i.e., the steady state terms of trade and the real exchange rate.

For convenience, and without loss of generality, we can assume that initial conditions (i.e., initial distribution of wealth) are such that $\frac{\alpha \vartheta}{\alpha^{*}}=1$. In that case, (55) implies that $\mathcal{S}=q(\mathcal{S})=1$, and $C=Y=\vartheta Y^{*}$. The latter condition implies zero net exports (i.e., balanced trade) in the new steady state.

One can view the small open economy setup used in the present paper as corresponding to the limiting case of $\alpha^{*} \rightarrow 0$ and $\vartheta \rightarrow 0$, though with a well defined ratio $\frac{\alpha^{*}}{\vartheta}=\alpha \in(0,1)$. 


\section{Appendix 2: Optimal Price Setting in the Calvo Model}

Following Calvo (1983) we assume that each individual firm resets its price with probability $1-\theta$ each period, independently of the time elapsed since the last adjustment. Thus, each period a measure $1-\theta$ of (randomly selected) firms reset their prices, while a fraction $\theta$ keep their prices unchanged. Let $\bar{P}_{H, t}(j)$ denote the price set by a firm $j$ adjusting its price in period $t$. Under the Calvo price-setting structure, $P_{H, t+k}(j)=\bar{P}_{H, t}(j)$ with probability $\theta^{k}$ for $k=0,1,2, \ldots$. Since all firms resetting prices in any given period will choose the same price, we henceforth drop the $j$ subscript.

When setting a new price in period $t$ firm $j$ seeks to maximize the current value of its dividend stream, conditional on that price being effective:

$$
\overline{\max }_{\bar{P}_{H, t}} \sum_{k=0}^{\infty} \theta^{k} E_{t}\left\{Q_{t, t+k}\left[Y_{t+k}\left(\bar{P}_{H, t}-M C_{t+k}^{n}\right)\right]\right\}
$$

subject to the sequence of demand constraints

$$
Y_{t+k}(j) \leq\left(\frac{\bar{P}_{H, t}}{P_{H, t+k}}\right)^{-\varepsilon}\left(C_{H, t+k}+C_{H, t+k}^{*}\right) \equiv Y_{t+k}^{d}\left(\bar{P}_{H, t}\right)
$$

where $M C_{t}^{n}=\frac{(1-\tau) W_{t}}{A_{t}}$ denotes the nominal marginal cost.

Thus, $\bar{P}_{H, t}$ must satisfy the first order condition

$$
\left.\sum_{k=0}^{\infty} \theta^{k} E_{t}\left\{Q_{t, t+k} Y_{t+k}\left(\bar{P}_{H, t}-\frac{\epsilon}{\epsilon-1} M C_{t+k}^{n}\right)\right]\right\}=0
$$

Using the fact that $Q_{t, t+k}=\beta^{k}\left(C_{t} / C_{t+k}\right)^{\sigma}\left(P_{t} / P_{t+k}\right)$, we can rewrite the previous condition as:

$$
\left.\sum_{k=0}^{\infty}(\beta \theta)^{k} E_{t}\left\{P_{t+k}^{-1} C_{t+k}^{-\sigma} Y_{t+k}\left(\bar{P}_{H, t}-\frac{\epsilon}{\epsilon-1} M C_{t+k}^{n}\right)\right]\right\}=0
$$

or, in terms of stationary variables,

$$
\sum_{k=0}^{\infty}(\beta \theta)^{k} E_{t}\left\{C_{t+k}^{-\sigma} Y_{t+k} \frac{P_{H, t-1}}{P_{t+k}}\left(\frac{\bar{P}_{H, t}}{P_{H, t-1}}-\frac{\epsilon}{\epsilon-1} \Pi_{t-1, t+k}^{H} M C_{t+k}\right)\right\}=0
$$

where $\Pi_{t-1, t+k}^{H} \equiv \frac{P_{H, t+k}}{P_{H, t-1}}$, and $M C_{t+k}=\frac{M C_{t+k}^{n}}{P_{H, t+k}}$. Log-linearizing the previous condition around the perfect foresight, zero inflation steady state with balanced trade we obtain:

$$
\bar{p}_{H, t}=p_{H, t-1}+\sum_{k=0}^{\infty}(\beta \theta)^{k} E_{t}\left\{\pi_{H, t+k}\right\}+(1-\beta \theta) \sum_{k=0}^{\infty}(\beta \theta)^{k} E_{t}\left\{\widehat{m c}_{t+k}\right\}
$$

where $\widehat{m c}_{t} \equiv m c_{t}-m c$ is the (log) deviation of real marginal cost from its steady state value $m c=-\log \frac{\varepsilon}{\varepsilon-1} \equiv-\mu$. 
Notice, that we can rewrite the previous expression in more compact form as:

$$
\bar{p}_{H, t}-p_{H, t-1}=\beta \theta E_{t}\left\{\bar{p}_{H, t+1}-p_{H, t}\right\}+\pi_{H, t}+(1-\beta \theta) \widehat{m c}_{t}
$$

Alternatively, using the relationship $\widehat{m c}_{t}=m c_{t}^{n}-p_{H, t}+\mu$ to substitute for $\widehat{m c}_{t}$ in (57), and after some straightforward algebra, we obtain a version of the price-setting rule in terms of expected nominal marginal costs:

$$
\bar{p}_{H, t}=\mu+(1-\beta \theta) \sum_{k=0}^{\infty}(\beta \theta)^{k} E_{t}\left\{m c_{t+k}^{n}\right\}
$$

which corresponds to expression (21) in the text.

Under the assumed price-setting structure, the dynamics of the domestic price index are described by the equation

$$
P_{H, t} \equiv\left[\theta P_{H, t-1}^{1-\varepsilon}+(1-\theta)\left(\bar{P}_{H, t}\right)^{1-\varepsilon}\right]^{\frac{1}{1-\varepsilon}}
$$

which can be log-linearized around the zero inflation steady state to yield,

$$
\pi_{H, t}=(1-\theta)\left(\bar{p}_{H, t}-p_{H, t-1}\right)
$$

Finally, we can combine the previous expression with (57) above to yield, after some algebra,

$$
\pi_{H, t}=\beta E_{t}\left\{\pi_{H, t+1}\right\}+\lambda \widehat{m c}_{t}
$$

where $\lambda \equiv \frac{(1-\theta)(1-\beta \theta)}{\theta}$, and which corresponds to (33) in the text.

The inflation equation for the world economy can be derived in an analogous manner. 


\section{Appendix 3: Derivation of the Welfare Loss Func- tion for the Special Case}

In the present appendix we derive a second order approximation of representative consumer's utility about the flexible price equilibrium allocation. function. As discussed in the main text, we eventually restrict our analysis to the special case of $\sigma=\eta=1$. For expository purposes we start with the general case. Below we make frequent use of the following second order approximation of percent deviations in terms of log deviations:

$$
\frac{Y_{t}-Y}{Y}=y_{t}+\frac{1}{2} y_{t}^{2}+o\left(\|a\|^{3}\right)
$$

where $o\left(\|a\|^{n}\right)$ represents terms that are of order higher than $n^{\text {th }}$, in the bound $\|a\|$ on the amplitude of the relevant shocks.

The approximation of $U\left(C_{t}\right)=\log C_{t}$ about the flexible price equilibrium yields:

$$
\begin{aligned}
U\left(C_{t}\right) & =\bar{c}_{t}+\widetilde{c}_{t}+o\left(\|a\|^{3}\right) \\
& =\bar{c}_{t}+(1-\alpha) \widetilde{y}_{t}+o\left(\|a\|^{3}\right)
\end{aligned}
$$

where $o\left(\|a\|^{3}\right)$ refers to terms of third or higher order. Notice that in deriving the second equality we have made use of (28) and the fact that $y_{t}^{*}$ is taken as exogenous by the monetary authority.

Similarly, and letting $\bar{V}_{t} \equiv V\left(\bar{N}_{t}\right)$, we have

$$
V\left(N_{t}\right)=\bar{V}_{t}+\bar{V}_{t}^{\prime} \bar{N}_{t}\left[\widetilde{n}_{t}+\frac{1}{2}(1+\varphi) \widetilde{n}_{t}^{2}\right]+o\left(\|a\|^{3}\right)
$$

The next step consists in rewriting the previous expression in terms of the output gap. Using the fact that $N_{t}=\left(\frac{Y_{t}}{A_{t}}\right) \int_{0}^{1}\left(\frac{P_{H, t}(i)}{P_{H, t}}\right)^{-\varepsilon} d i$, we have

$$
\widetilde{n}_{t}=\widetilde{y}_{t}+u_{t}
$$

where $u_{t} \equiv \log \int_{0}^{1}\left(\frac{P_{H, t}(i)}{P_{H, t}}\right)^{-\varepsilon} d i$. The following lemma shows that $u_{t}$ is proportional to the cross-sectional distribution of relative prices (and, hence, of second order).

Lemma 1: $u_{t}=\frac{\varepsilon}{2} \operatorname{var}_{i}\left\{p_{H, t}(i)\right\}+o\left(\|a\|^{3}\right)$.

Proof: Let $\widehat{p}_{H, t}(i) \equiv p_{H, t}(i)-p_{H, t}$. Notice that,

$$
\begin{aligned}
\left(\frac{P_{H, t}(i)}{P_{H, t}}\right)^{1-\varepsilon} & =\exp \left[(1-\varepsilon) \widehat{p}_{H, t}(i)\right] \\
& =1+(1-\varepsilon) \widehat{p}_{H, t}(i)+\frac{(1-\varepsilon)^{2}}{2} \widehat{p}_{H, t}(i)^{2}+o\left(\|a\|^{3}\right)
\end{aligned}
$$


Furthermore, from the definition of $P_{H, t}$, we have $1=\int_{0}^{1}\left(\frac{P_{H, t}(i)}{P_{H, t}}\right)^{1-\varepsilon} d i$. Hence, it follows that

$$
E_{i}\left\{\widehat{p}_{H, t}(i)\right\}=\frac{(\varepsilon-1)}{2} E_{i}\left\{\widehat{p}_{H, t}(i)^{2}\right\}
$$

In addition, a second order approximation to $\left(\frac{P_{H, t}(i)}{P_{H, t}}\right)^{-\varepsilon}$, yields:

$$
\left(\frac{P_{H, t}(i)}{P_{H, t}}\right)^{-\varepsilon}=1-\varepsilon \widehat{p}_{H, t}(i)+\frac{\varepsilon^{2}}{2} \widehat{p}_{H, t}(i)^{2}+o\left(\|a\|^{3}\right)
$$

Combining the two previous results, it follows that

$$
\begin{aligned}
\int_{0}^{1}\left(\frac{P_{H, t}(i)}{P_{H, t}}\right)^{-\varepsilon} d i & =1+\frac{\varepsilon}{2} E_{i}\left\{\widehat{p}_{H, t}(i)^{2}\right\} \\
& =1+\frac{\varepsilon}{2} \operatorname{var}_{i}\left\{p_{H, t}(i)\right\}
\end{aligned}
$$

from which follows that $u_{t}=\frac{\varepsilon}{2} \operatorname{var}_{i}\left\{p_{H, t}(i)\right\}+o\left(\|a\|^{3}\right)$.

We can thus rewrite the second order approximation to the disutility of labor as:

$$
V\left(N_{t}\right)=\bar{V}_{t}+\bar{V}_{t}^{\prime} \bar{N}_{t}\left[\widetilde{y}_{t}+u_{t}+\frac{1}{2}(1+\varphi) \widetilde{y}_{t}^{2}\right]+o\left(\|a\|^{3}\right)
$$

Under the optimal subsidy scheme assumed, the optimality condition $\bar{V}_{t}^{\prime} \bar{N}_{t}=$ $(1-\alpha)$ holds for all $t$, allowing us to rewrite the period utility as:

$$
U\left(C_{t}\right)-V\left(N_{t}\right)=-(1-\alpha)\left[u_{t}+\frac{1}{2}(1+\varphi) \widetilde{y}_{t}^{2}\right]+t . i . p .+o\left(\|a\|^{3}\right)
$$

where t.i.p. denotes terms independent of policy.

Lemma 2: $\sum_{t=0}^{\infty} \beta^{t} \operatorname{var}_{i}\left\{p_{H, t}(i)\right\}=\frac{1}{\lambda} \sum_{t=0}^{\infty} \beta^{t} \pi_{H, t}^{2}$, where $\lambda \equiv \frac{(1-\theta)(1-\beta \theta)}{\theta}$

Proof: Woodford (2001, NBER WP8071), pp 22-23.

Collecting all the previous results, we can write the second order approximation to the small open economy's consumer's utility function as follows:

$$
\mathbb{W} \equiv-\frac{(1-\alpha)}{2} \sum_{t=0}^{\infty} \beta^{t}\left[\frac{\varepsilon}{\lambda} \pi_{H, t}^{2}+(1+\varphi) \widetilde{y}_{t}^{2}\right]+t . i . p .+o\left(\|a\|^{3}\right)
$$

which is equation (52) in the text. 


\section{References}

Bacchetta, Philippe, and Eric van Wincoop (2000): "Does Exchange Rate Stability Increase Trade and Welfare?", American Economic Review, 90:5, 1093-1109

Backus, David and G. Smith: "Consumption and Real exchange Rates in Dynamic Exchange Economies with Nontraded Goods", Journal of International Economics 35:297-316.

Backus, David, P.K Kehoe and F. E. Kydland (1995): "International Business Cycles: Theory and Evidence", in Frontiers of Business Cycle Research, Edited by Thomas F. Cooley, Princeton University Press.

Ball, Laurence (1999): "Policy Rules for Open Economies," in J.B. Taylor ed., Monetary Policy Rules, University of Chicago Press.

Benhabib, Jess, Stephanie Schmitt-Grohé, and Martín Uribe (2001) "The Perils of Taylor Rules", Journal of Economic Theory 96, January/February 2001, 40-69.

Benigno, Gianluca and Pierpaolo Benigno (2001): "Price Stability in Open Economies", mimeo.

Benigno, Pierpaolo (1999): "Optimal Monetary Policy in a Currency Area", mimeo.

Betts, Caroline and Michael B. Devereux (1996): "The Exchange Rate in a Model of Pricing-to-Market," European Economic Review 40, 1996.

Betts, Caroline and Michael B. Devereux (2000): "Exchange Rate Dynamics in a Model of Pricing-to-Market", Journal of International Economics 50,1,215-244.

Bullard, James and K. Mitra (2001): "Learning About Monetary Policy Rules", Journal of Monetary Economics, forthcoming.

Calvo, Guillermo, 1983, "Staggered Prices in a Utility Maximizing Framework," Journal of Monetary Economics, 12, 383-398.

Chari, V.V., Patrick Kehoe, and Ellen McGrattan (1998): "Monetary Shocks and Real Exchange Rates in Sticky Price Models of International Business Cycles," mimeo.

Clarida, Richard, Jordi Galí, and Mark Gertler (1998): "Monetary Policy Rules in Practice: Some International Evidence" European Economic Review, vol. 42, 10331067.

Clarida, Richard, Jordi Galí, and Mark Gertler (1999): "The Science of Monetary Policy: A New Keynesian Perspective," Journal of Economic Literature, vol. 37, 1661-1707.

Clarida, Richard, Jordi Galí, and Mark Gertler (2000): "Monetary Policy Rules and Macroeconomic Stability: Evidence and Some Theory," Quarterly Journal of Economics, vol. 105, issue 1, 147-180.

Clarida, Richard, Jordi Galí, and Mark Gertler (2001): "Optimal Monetary Policy in Open vs. Closed Economies: An Integrated Approach," American Economic Review, vol. 91, no. 2, 248-252.

Corsetti, Giancarlo and Paolo Pesenti (2001a): "Welfare and Macroeconomic Interdependence," Quarterly Journal of Economics vol. CXVI,issue 2, 421-446.

Corsetti, Giancarlo and Paolo Pesenti (2001b): "International Dimensions of Optimal Monetary Policy", mimeo. 
Devereux, Michael B. and Charles Engel (1998): "Fixed vs. Floating Exchange Rates: How Price Setting Affects the Optimal Choice of Exchange Rate Regime," mimeo.

Devereux, Michael B. and Charles Engel (2001): "Exchange Rate Pass-Through, Exchange Rate Volatility, and Exchange Rate Disconnect", mimeo.

Erceg Christopher J., D.W. Henderson and A.T. Levine (2000): "Optimal Monetary Policy with Staggered Wage and Price Contracts", Journal of Monetary Economics 46 281-313.

Galí, Jordi and Mark Gertler (1999): "Inflation Dynamics: A Structural Econometric Analysis," Journal of Monetary Economics, vol. 44, no. 2, 195-222.

Galí, Jordi, and Tommaso Monacelli (2000): "Monetary Policy Coordination and Exchange Rate Volatility in a Two Country Model," work in progress.

Goodfriend, Marvin and Robert G. King (2001): "The Case for Price Stability," in Garcia-Herrero et al. (eds.) Why Price Stability? European Central Bank.

Hau, Harald (2000): "Real Exchange Rate Volatility and Economic Openness: Theory and Evidence", unpublished manuscript.

Judd, John P., and Glenn Rudebusch (1998): "Taylor's Rule and the Fed: A Tale of Three Chairmen," mimeo.

King, Robert G., and Alexander L. Wolman (1996): "Inflation Targeting in a St. Louis Model of the 21st Century," Federal Reserve Bank of St. Louis Review, vol. 78, no. 3. (NBER WP \#5507).

Kollmann, Robert (2001): "The Exchange Rate in a Dynamic Optimizing Current Account Model with Nominal Rigidities: A Quantitative Investigation," Journal of International Economics vol.55, 243-262.

Lane, Philip R. (1999): "The New Open Economy Macroeconomics: A Survey," Journal of International Economics, vol. 54, 235-266.

McCallum Bennet and Edward Nelson (2000) "Monetary Policy for an Open Economy: An Alternative Framework with Optimizing Agents and Sticky Prices", Oxford Review of Economic Policy 16, 74-91.

Monacelli, Tommaso (1999): "Into the Mussa Puzzle: Monetary Policy Regimes and the Real Exchange Rate in a Small Open Economy" mimeo.

Obstfeld, Maurice and Kenneth Rogoff (1995): "Exchange Rate Dynamics Redux," Journal of Political Economy 103, no. 3, 624-660.

Obstfeld, Maurice and Kenneth Rogoff (1999): "New Directions for Stochastic Open Economy Models," Journal of International Economics, vol. 50, no. 1, 117153.

Orphanides, Athanasios (1999): "The Quest for Prosperity Without Inflation" mimeo.

Pappa, Evi (2001): "Should the Fed and the ECB Cooperate? Optimal Monetary Policy in a Two-Country World," mimeo.

Parrado, Eric and Andrés Velasco (2002): "Optimal Interest Rate Policy in a Small Open Economy," NBER WP\# 8721.

Rotemberg, Julio and Michael Woodford (1999): "Interest Rate Rules in an Estimated Sticky Price Model," in J.B. Taylor ed., Monetary Policy Rules, University of Chicago Press. 
Sbordone, Argia (1998): "Prices and Unit Labor Costs: Testing Models of Pricing Behavior," mimeo.

Schmitt-Grohé Stephanie and Martín Uribe (1999): "Stabilization Policy and the Costs of Dollarization", mimeo.

Schmitt-Grohé Stephanie and Martín Uribe (2001): "Optimal Fiscal and Monetary Policy Under Sticky Prices", mimeo.

Svensson, Lars E.O. (2000): "Open-Economy Inflation Targeting," Journal of International Economics, vol. 50, no. 1.

Taylor, John B. (1993): "Discretion versus Policy Rules in Practice," CarnegieRochester Series on Public Policy 39, 195-214.

Taylor, John B. editor (1999): Monetary Policy Rules, University of Chicago Press.

Vestin, D. (1999): "Price level Targeting versus Inflation Targeting in a Forward Looking Model," unpublished manuscript, IIES, Stockholm University.

Woodford, Michael (2000), Interest and Prices, chapter 2, mimeo.

Yun, Tack (1996), "Monetary Policy, Nominal Price Rigidity, and Business Cycles", Journal of Monetary Economics, 37:345-70. 
Table 1

Macroeconomic Volatility under Alternative Monetary Policy Regimes

\begin{tabular}{|c|c|c|c|c|c|c|c|c|c|}
\hline \multirow[b]{2}{*}{ shocks } & \multicolumn{3}{|c|}{ DIT } & \multicolumn{3}{|c|}{ CIT } & \multicolumn{3}{|c|}{ PEG } \\
\hline & domestic & foreign & both & domestic & foreign & both & domestic & foreign & both \\
\hline Output Gap & 0.000 & 0.000 & 0.000 & 0.425 & 0.425 & 0.286 & 0.635 & 0.635 & 0.428 \\
\hline Domestic Inflation & 0.000 & 0.000 & 0.000 & 0.210 & 0.210 & 0.142 & 0.397 & 0.397 & 0.267 \\
\hline Output & 2.007 & 0.000 & 2.007 & 1.791 & 0.425 & 1.971 & 1.647 & 0.635 & 1.955 \\
\hline CPI Inflation & 0.359 & 0.359 & 0.242 & 0.000 & 0.000 & 0.000 & 0.238 & 0.238 & 0.160 \\
\hline Nominal I. Rate & 0.201 & 0.000 & 0.201 & 0.124 & 0.215 & 0.212 & 0.000 & 0.201 & 0.201 \\
\hline Real Ex. Rate & 1.204 & 1.204 & 0.812 & 1.074 & 1.074 & 0.724 & 0.988 & 0.988 & 0.666 \\
\hline Nominal Ex. Rate & 2.007 & 2.007 & 1.353 & 1.074 & 1.074 & 0.724 & 0.000 & 0.000 & 0.000 \\
\hline
\end{tabular}


Table 2

Contribution to Welfare Loss

\begin{tabular}{|c|c|c|c|c|c|c|}
\hline$\mu=1.2, \varphi=3$ & bench & & & & & \\
\hline & \multicolumn{3}{|c|}{ CIT } & \multicolumn{3}{|c|}{ PEG } \\
\hline shocks & domestic & foreign & both & domestic & foreign & both \\
\hline Var(Domestic Inflation) & -0.009 & -0.009 & -0.004 & -0.033 & -0.033 & -0.015 \\
\hline Var(Output Gap) & -0.002 & -0.002 & -0.001 & -0.005 & -0.005 & -0.002 \\
\hline Total & -0.011 & -0.011 & -0.005 & -0.038 & -0.038 & -0.017 \\
\hline
\end{tabular}

\begin{tabular}{|c|c|c|c|c|c|c|}
\hline \multicolumn{7}{|c|}{ low steady-state markup } \\
\hline & \multicolumn{3}{|c|}{ CIT } & \multicolumn{3}{|c|}{ PEG } \\
\hline shocks & domestic & foreign & both & domestic & foreign & both \\
\hline $\operatorname{Var}($ Domestic Inflation) & -0.017 & -0.017 & -0.008 & -0.061 & -0.061 & -0.027 \\
\hline Var(Output Gap) & -0.002 & -0.002 & -0.001 & -0.005 & -0.005 & -0.002 \\
\hline Total & -0.019 & -0.019 & -0.009 & -0.065 & -0.065 & -0.030 \\
\hline
\end{tabular}

\begin{tabular}{|c|c|c|c|c|c|c|}
\hline \multicolumn{7}{|c|}{ low elasticity of labor supply } \\
\hline & \multicolumn{3}{|c|}{ CIT } & \multicolumn{3}{|c|}{ PEG } \\
\hline shocks & domestic & foreign & both & domestic & foreign & both \\
\hline $\operatorname{Var}($ Domestic Inflation) & -0.015 & -0.015 & -0.007 & -0.061 & -0.061 & -0.028 \\
\hline Var(Output Gap) & -0.002 & -0.002 & -0.001 & -0.005 & -0.005 & -0.002 \\
\hline Total & -0.017 & -0.017 & -0.008 & -0.067 & -0.067 & -0.030 \\
\hline
\end{tabular}

\begin{tabular}{|c|c|c|c|c|c|c|}
\hline \multicolumn{7}{|c|}{ low markup and elasticity of labor supply } \\
\hline & \multicolumn{3}{|c|}{ CIT } & \multicolumn{3}{|c|}{ PEG } \\
\hline shocks & domestic & foreign & both & domestic & foreign & both \\
\hline Var(Domestic Inflation) & -0.027 & -0.027 & -0.012 & -0.112 & -0.112 & -0.051 \\
\hline Var(Output Gap) & -0.002 & -0.002 & -0.001 & -0.005 & -0.005 & -0.002 \\
\hline Total & -0.029 & -0.029 & -0.013 & -0.118 & -0.118 & -0.053 \\
\hline
\end{tabular}

Note: entries are percentage units of steady-state consumption 


\section{Fig.1 Impulse Responses to a Domestic Productivity Shock \\ Output Gap \\ Domestic Inflation}

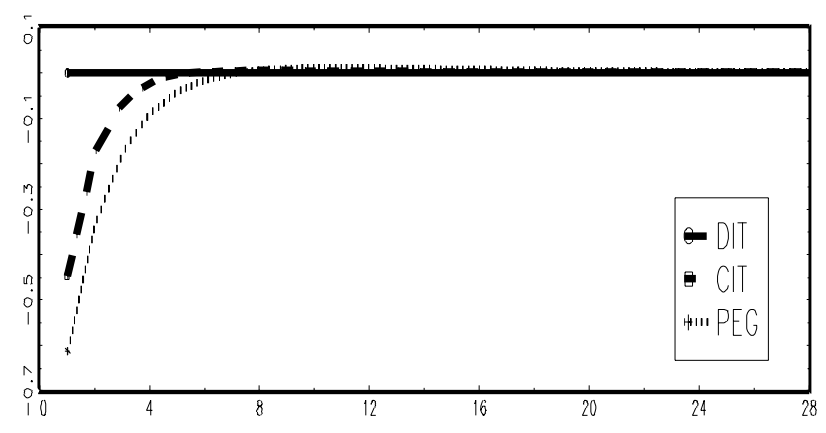

Nominal Interest Rate

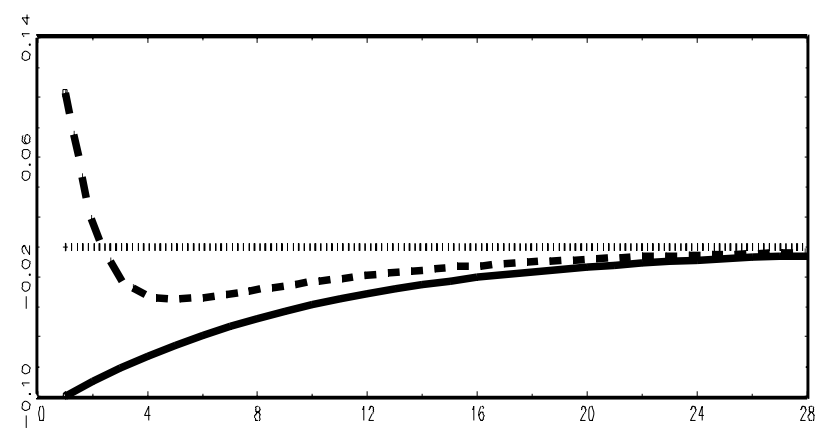

Nominal Exchange Rate

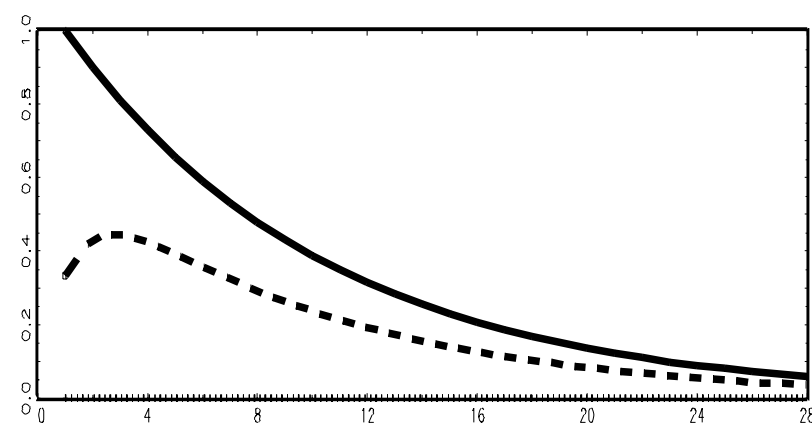

Domestic Price Level

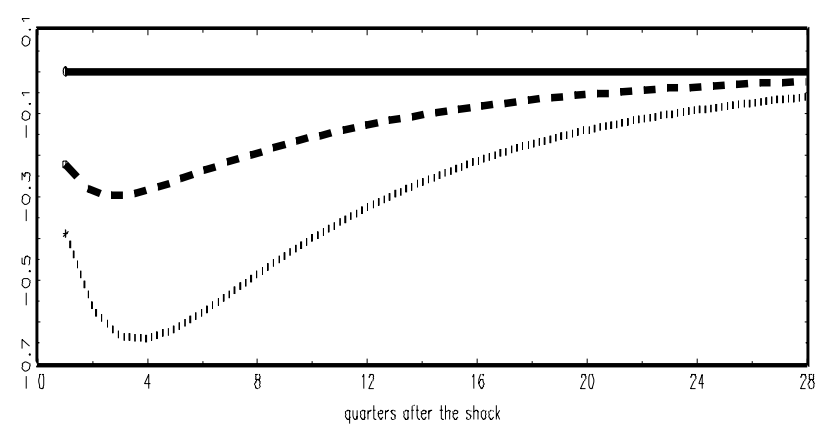

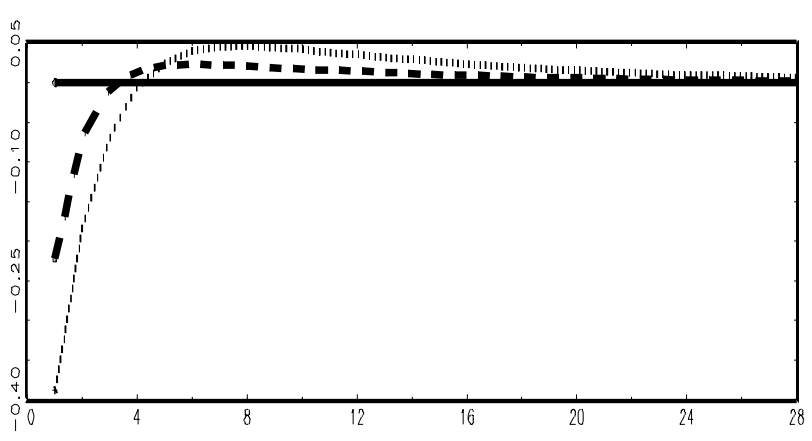

CPI Inflation

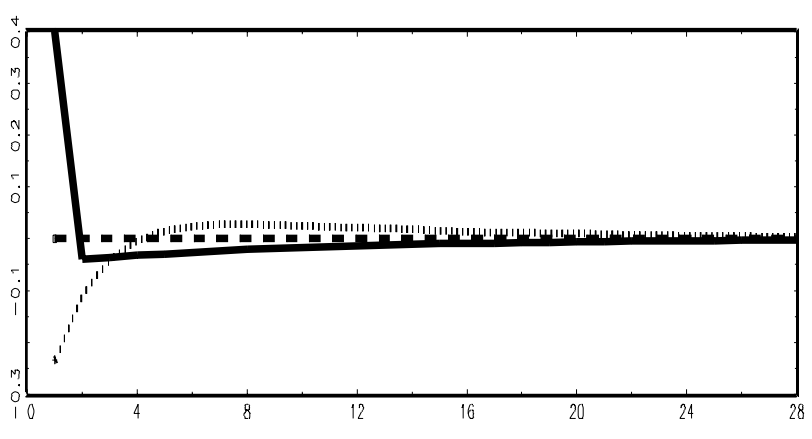

Real Exchange Rate

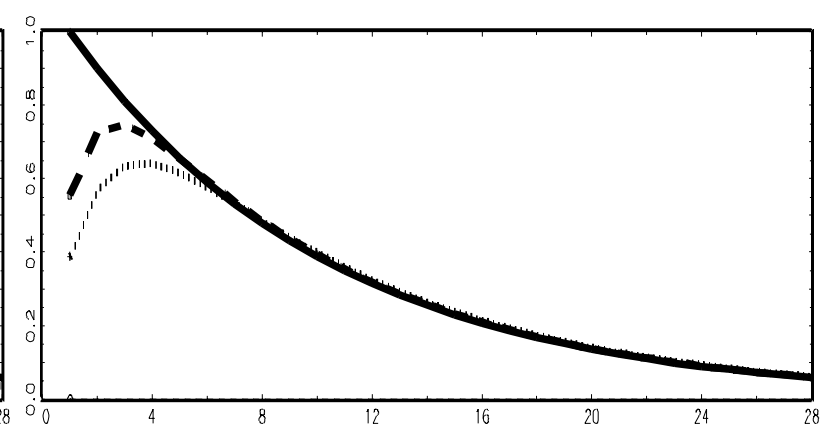

CPI Level

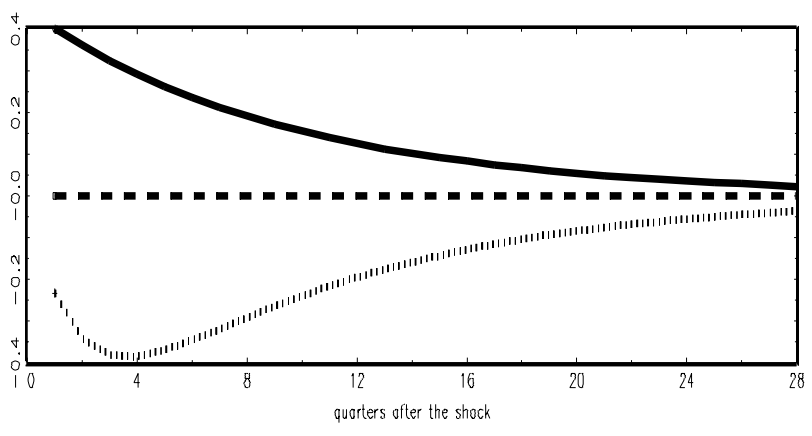




\section{Fig.2 Effect on Volatility of Varying the Elasticity of Substitution}

\section{Output Gap}

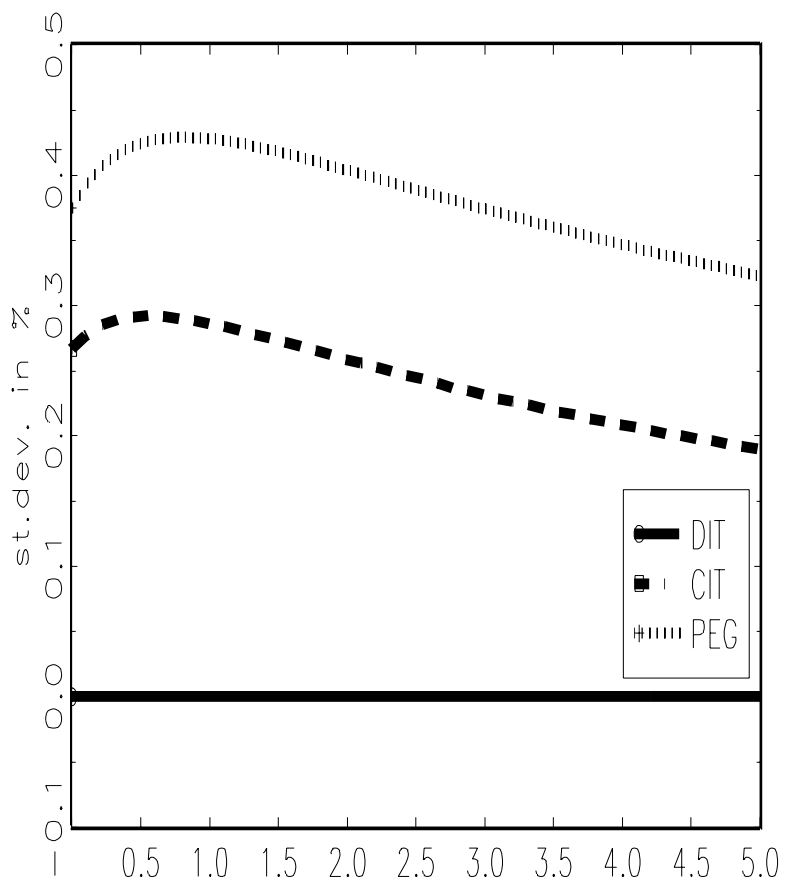

Nominal Exchange Rate

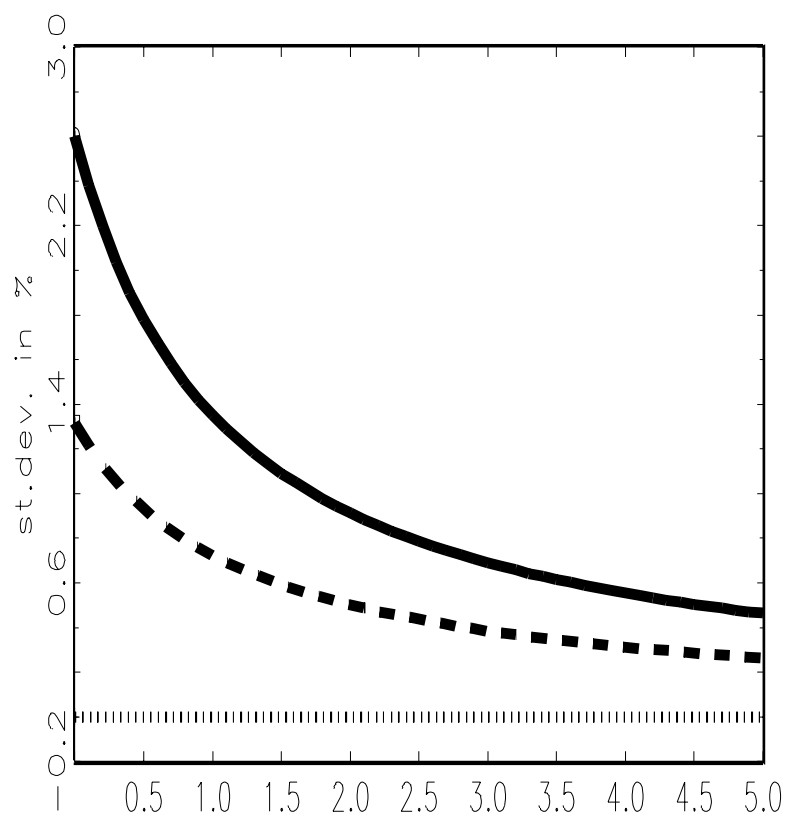

elasticity of substitution btw. $\mathrm{H}$ and $\mathrm{F}$ goods
Domestic Inflation
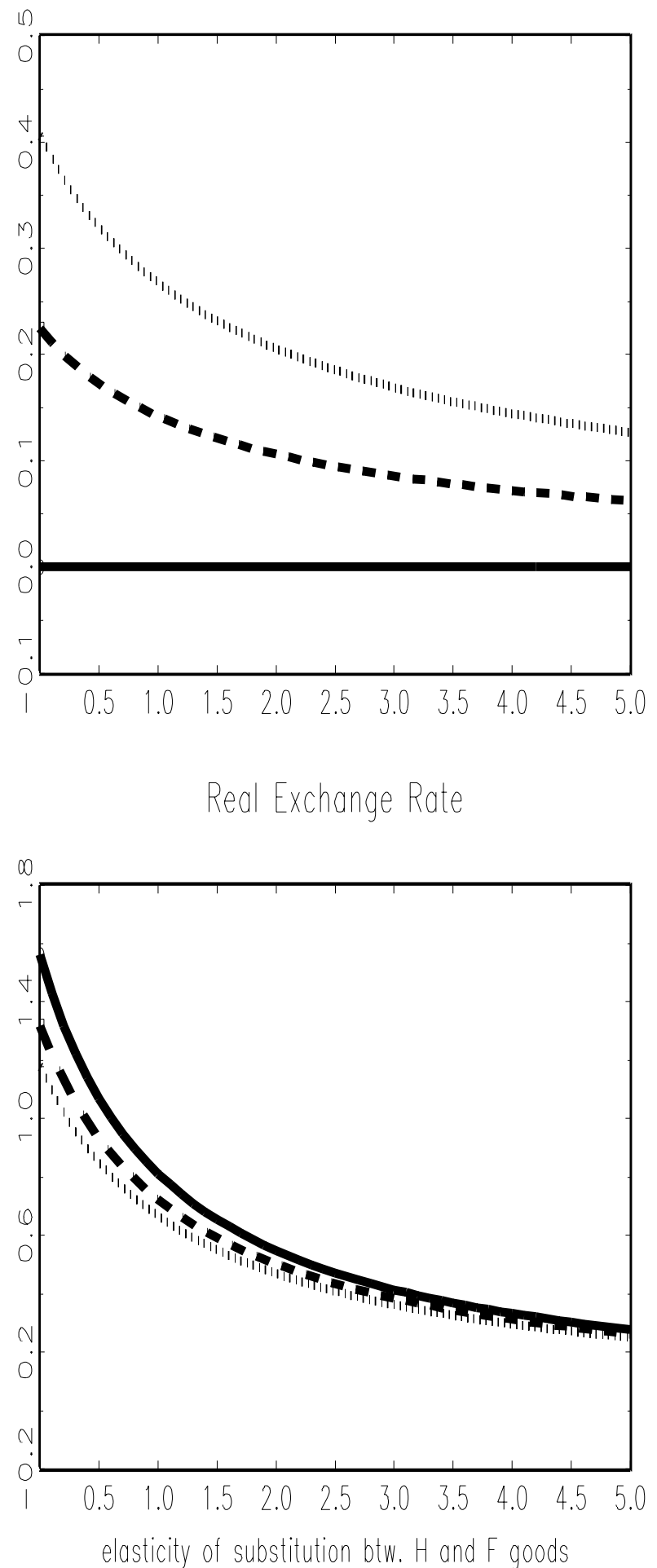


\section{Fig.3 Effect on Volatility of Varying Openness}

Output Gap

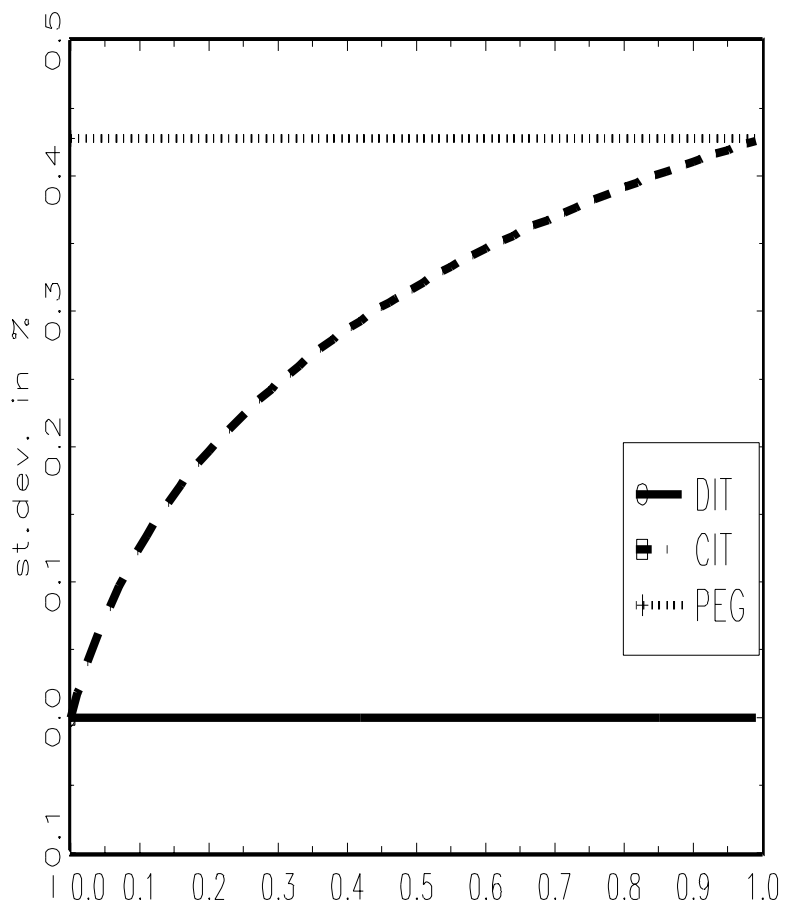

Nominal Exchange Rate

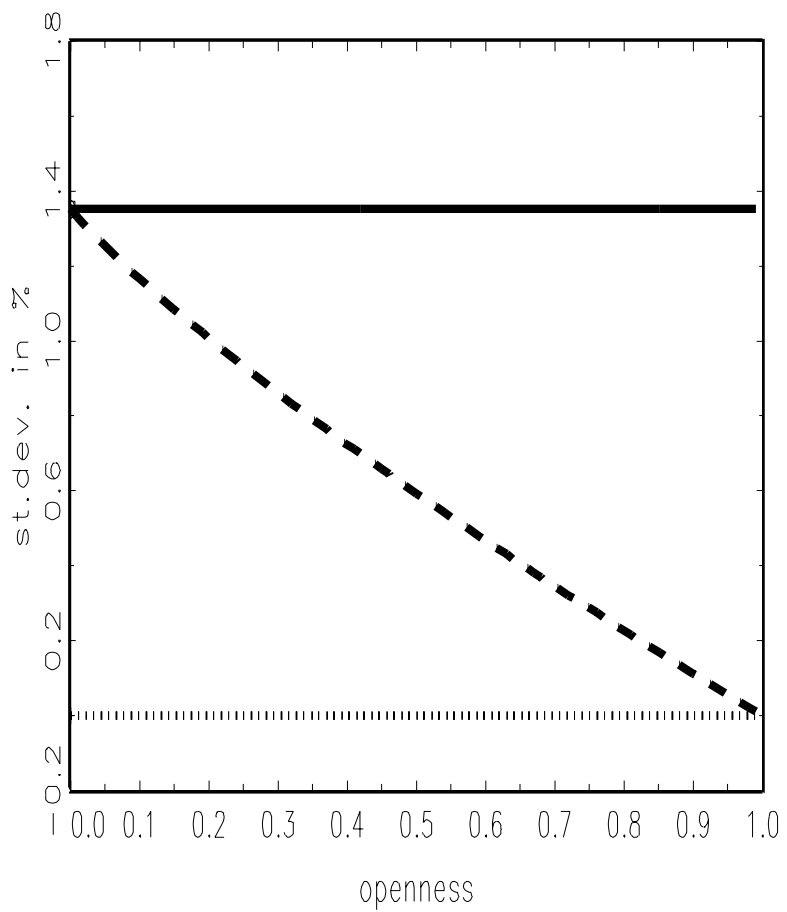

Domestic Inflation

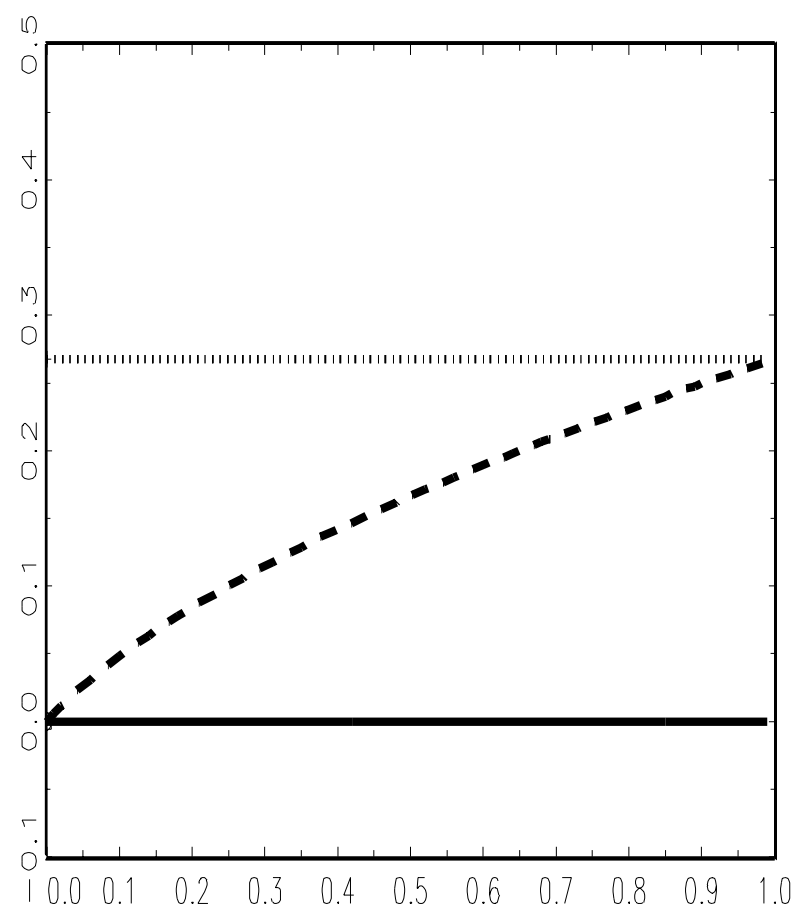

Real Exchange Rate

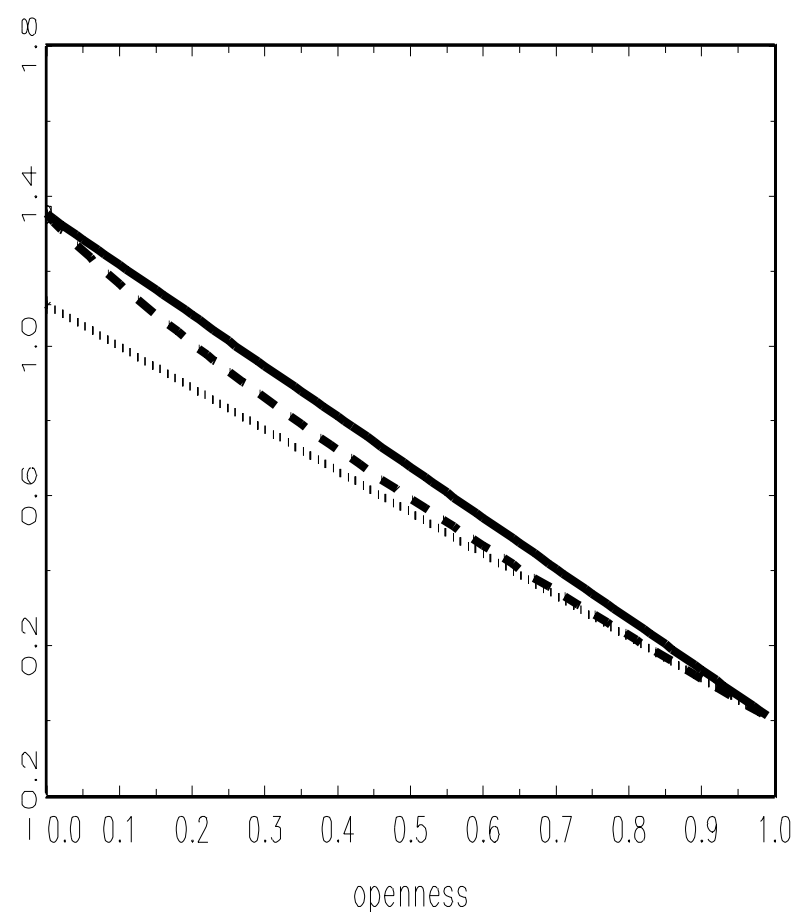




\section{Fig.4 Effect on Volatility of Varying Price Stickiness}

\section{Output Gap}

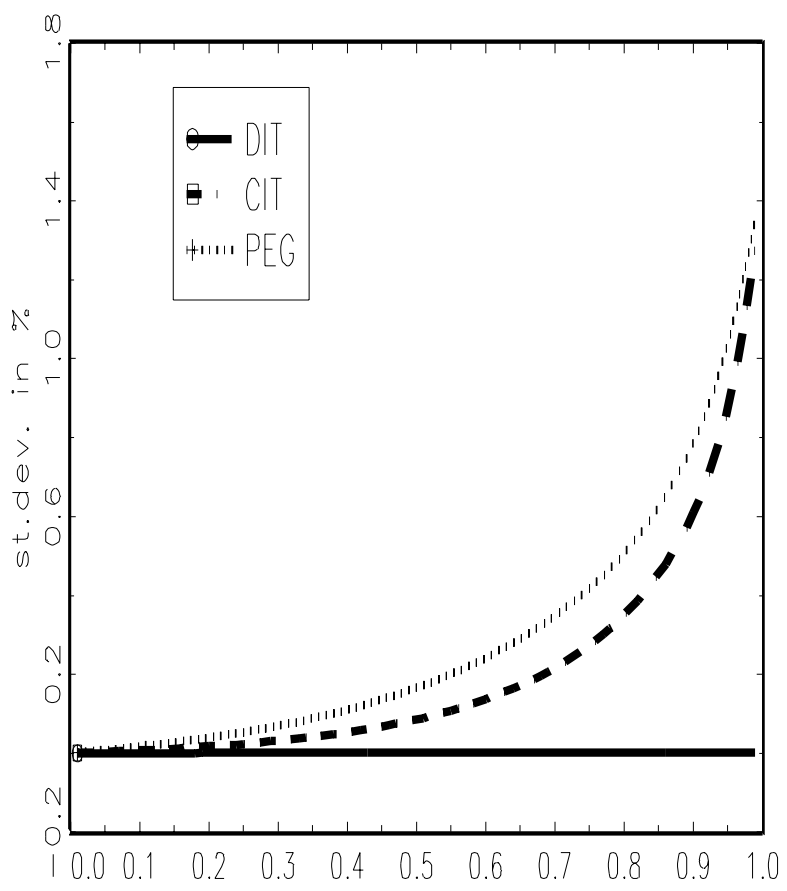

Nominal Exchange Rote

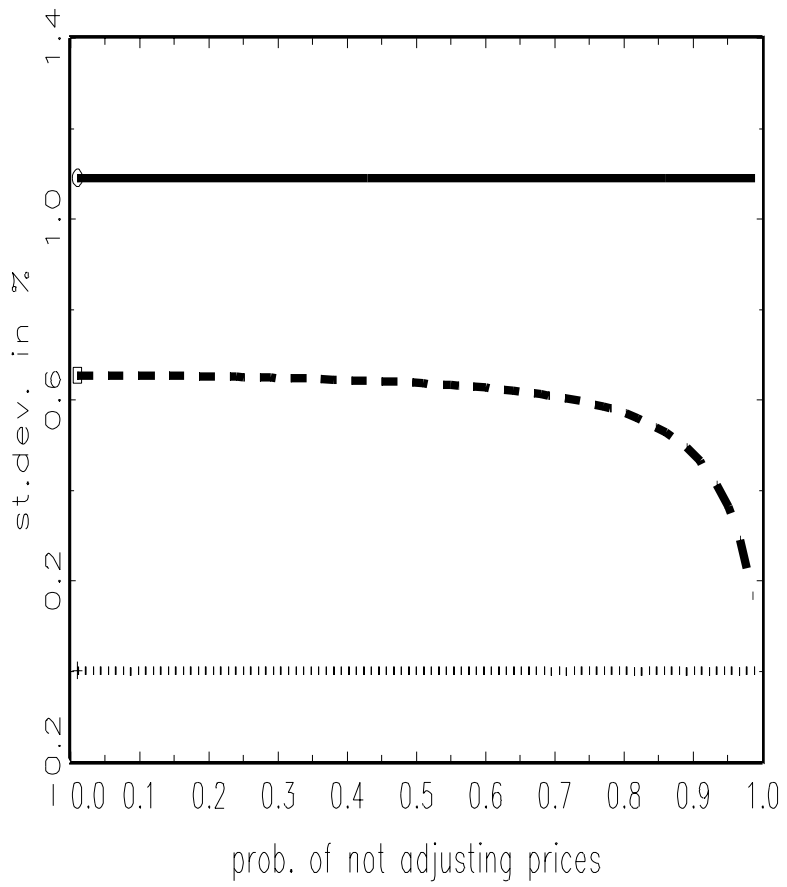

Domestic Inflation

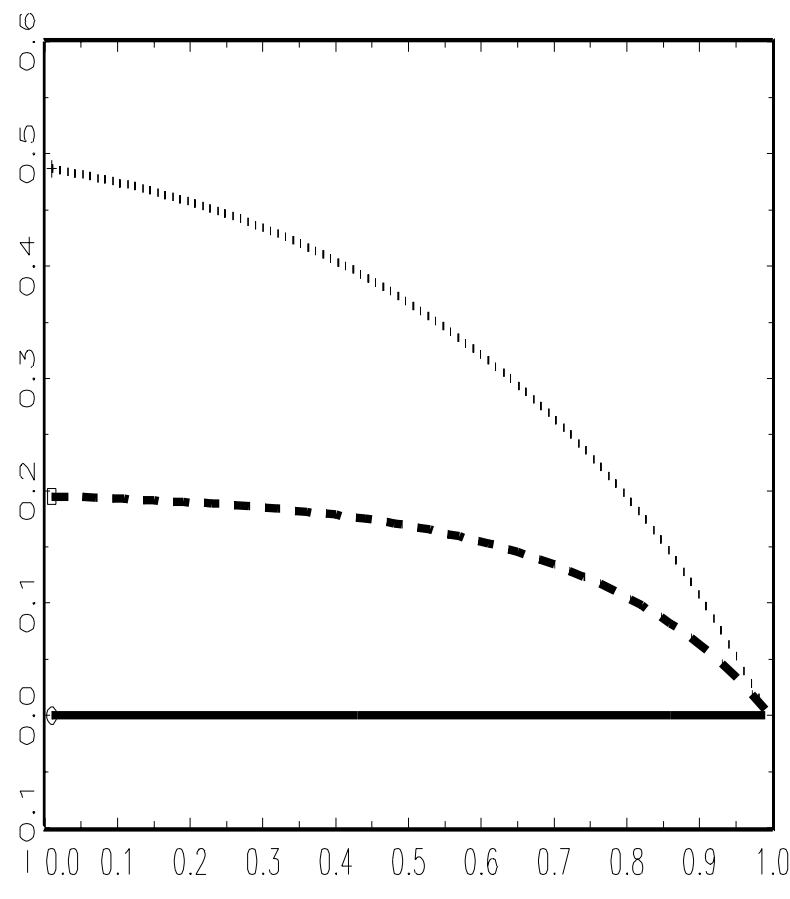

Real Exchange Rate

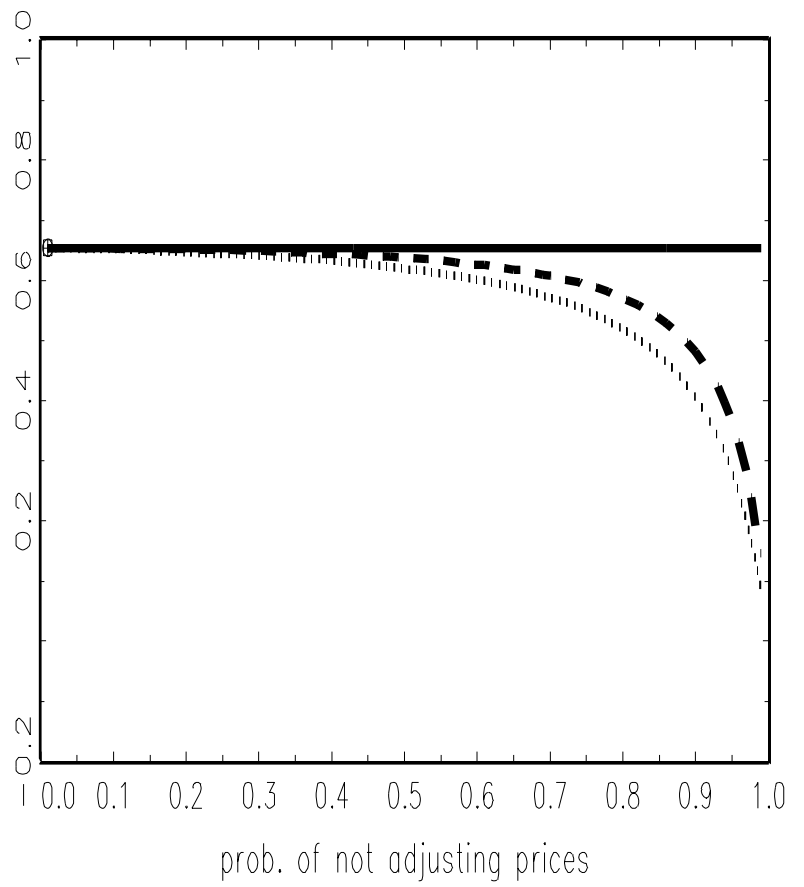


Fig.5 Effect on Welfare of Varying Openness

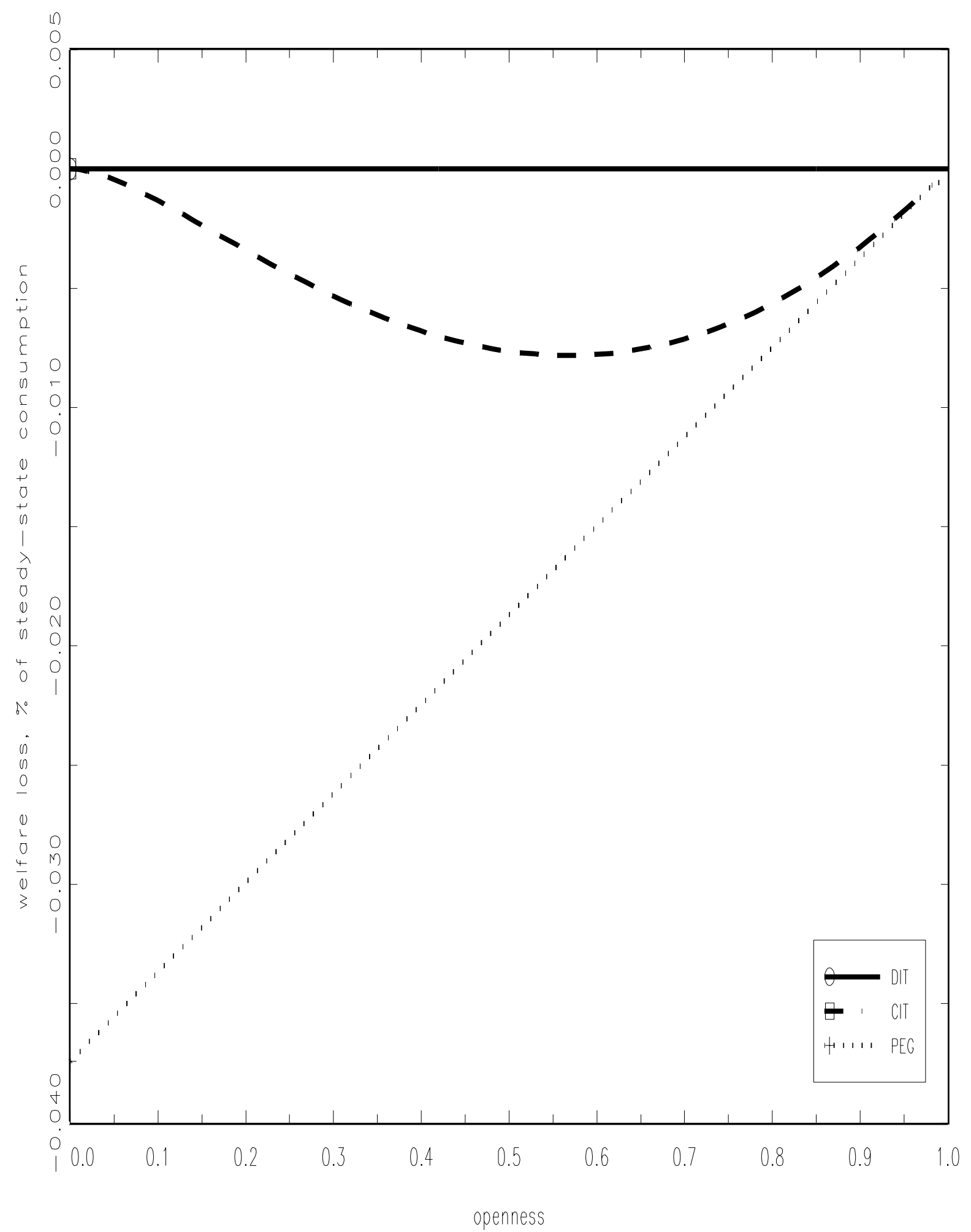


Fig.6 Effect on Welfare of Varying the Cross-Country Correlation of Shocks

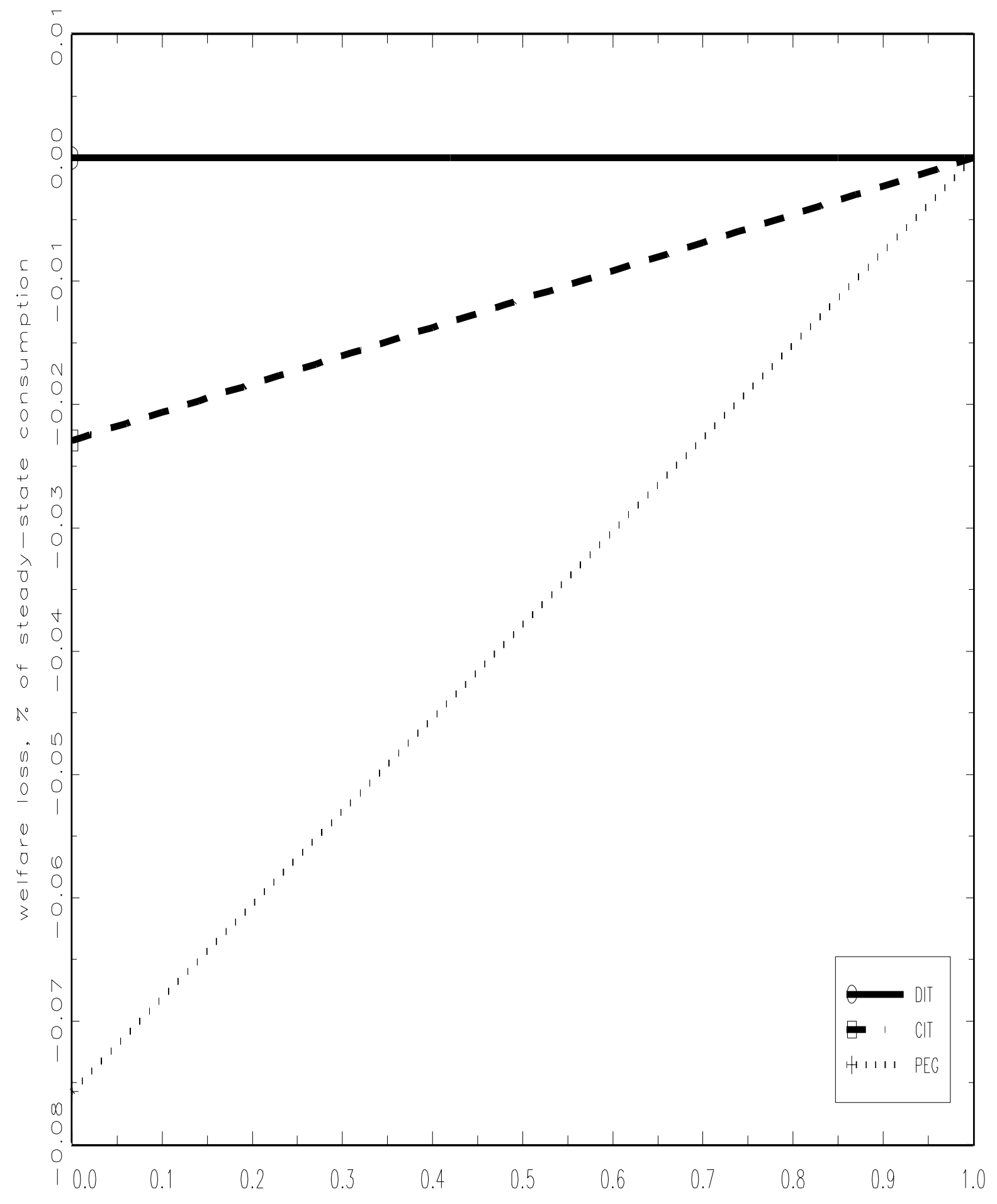

cross-country correlation of shocks 